Submitted for publication in Journal of Catalysis

\title{
Mechanistic Interpretation of the Effects of Acid Strength on Alkane Isomerization Turnover Rates and Selectivity
}

\author{
William Knaeble, Robert T. Carr, and Enrique Iglesia* \\ Department of Chemical and Biomolecular Engineering \\ University of California \\ Berkeley, CA, 94720
}

*Corresponding Author: Fax: + 1 510-642-4778; Email: iglesia@berkeley.edu 


\begin{abstract}
Acid strength effects on alkane isomerization turnover rates and selectivities are probed using hexene isomers as reactants on bifunctional catalysts containing tungsten Keggin polyoxometalates (POM) with different central atoms and exhibiting well-defined structures amenable to reliable estimates of deprotonation energies (DPE) as rigorous descriptors of acid strength. Titrations of protons with hindered bases during catalysis and mechanistic interpretations of rate data on POM acids in terms of a common sequence of elementary steps give isomerization rate constants that decrease exponentially with increasing DPE. The sensitivity to acid strength is the same for all interconversions among isomeric hexenes because their respective transition states are similar in the amount and localized character of their cationic charges, which determine, in turn, the extent to which the ionic and covalent interactions that determine DPE are recovered upon formation of ion-pairs at transition states. The ratios of rate constants for such interconversions, and thus selectivities, are independent of acid strength and their magnitude merely reflects the stability of the gaseous analogs of their respective transition states on all acids.
\end{abstract}

Keywords:

Keggin Polyoxometalates; Heteropolyacids; Skeletal Isomerization; Bifunctional Catalysis; Acid Strength; Deprotonation Energy; Ion-pair Transition State Theory; 


\section{Introduction}

Catalysis by solid Brønsted acids is ubiquitous in the synthesis and upgrading of fuels and petrochemicals [1]. Rigorous connections between the structure and strength of acid sites and their specific consequences for reactivity and selectivity remain imprecise and often contradictory. Prevailing uncertainties about the number, location, and structure of acid sites during catalysis, the challenges inherent in the unambiguous experimental assessment of acid strength, and measured rates and selectivities that are seldom interpreted in terms of chemical mechanisms have contributed to the pervasive controversies about the strength of acids and about the consequences of acid strength for rates and selectivities of specific reactions and for catalysis in general.

Deprotonation energies (DPE) reflect the ionic and covalent interactions between a proton $\left(\mathrm{H}^{+}\right)$and its conjugate base. These interactions must be overcome to transfer this proton to the intermediates and transition states that mediate transformations catalyzed by acids. DPE values represent a rigorous and probe-independent measure of acid strength; it is accessible to density functional theory (DFT) treatments for well-defined solid acids, such as Keggin polyoxometalate $(\mathrm{POM})$ clusters $\left(1087-1143 \mathrm{~kJ} \mathrm{~mol}^{-1}\right.$ for $\mathrm{H}_{8}$ ${ }_{\mathrm{n}} \mathrm{X}^{\mathrm{n}+} \mathrm{W}_{12} \mathrm{O}_{40} ; \mathrm{X}=\mathrm{P}, \mathrm{Si}, \mathrm{Al}$, or Co in order of increasing DPE) [2, 3] and zeolites with different frameworks [4] and heteroatoms [5].

The effects of DPE, and consequently of acid strength, on alkanol dehydration [3, $6,7]$ and n-hexene isomerization [8] rate constants (per accessible $\mathrm{H}^{+}$) on Keggin POM clusters $\left(\mathrm{H}_{8-\mathrm{n}} \mathrm{X}^{\mathrm{n}+} \mathrm{W}_{12} \mathrm{O}_{40} ; \mathrm{X}=\mathrm{P}, \mathrm{Si}, \mathrm{Al}\right.$, or $\left.\mathrm{Co}\right)$ indicate that the ion-pair transition states (TS) that mediate the kinetically-relevant elementary steps are lower in energy with respect to fully protonated clusters on stronger acids, in part, because of their more stable 
conjugate anions. Differences in the amount and localization of cationic charge at kinetically relevant TS relative to those properties for the most abundant surface intermediates (MASI) determine the sensitivity of measured rate constants to acid strength $[7,8]$. Cations that are small and contain a highly localized charge resemble $\mathrm{H}^{+}$ and interact most effectively with the conjugate anion [9]; as a result, proton-like TS structures attenuate the effects of acid strength on reactivity most effectively, by recovering most of the energy required to separate the proton. These studies have shown that the effects of acid strength on reactivity reflect differences in interaction energies between the TS and the conjugate anion and those between the MASI species and the conjugate anion.

Here, we assess the effects of acid strength on isomerization turnover rates of hexane and hexene isomers with different backbone structures on bifunctional catalyst mixtures consisting of well-defined Brønsted acids (W-based Keggin POM clusters) and metal sites (here $\mathrm{Pt} / \mathrm{Al}_{2} \mathrm{O}_{3}$ ). In such mixtures, $\mathrm{Pt}$ sites equilibrate alkanes and alkenes with a given backbone structure via fast hydrogenation-dehydrogenation reactions when such sites are present in sufficient amounts; in such cases, reactant alkenes are present throughout the catalyst mixture at low and constant concentrations; such low concentrations cannot be detected but are known from thermodynamic data at each given temperature and $\mathrm{H}_{2}$ and alkane pressures. These alkenes undergo skeletal isomerization on acid sites and the alkene isomers formed rapidly equilibrate with the respective alkanes upon contact with Pt sites [10,11, 12].

Isomerization rate constants $\left(\right.$ per $\mathrm{H}^{+}$) were measured for the conversion of 2 methylpentane, 3-methylpentane, 2,3-dimethylbutane, and n-hexane reactants through 
mechanistic interpretations of rate data and measurements of the number of accessible protons by titrations with organic bases during catalysis. These rate constants reflect TS energies relative to unoccupied Brønsted acid sites and gaseous alkene reactants. Selectivities to isomerization products formed from reactant-derived alkenes after only a single sojourn at an acid site cannot be estimated directly from measured selectivities, because secondary interconversions of alkene products and hydrogenation reactions occur at comparable rates; hydrogenation occurs, either locally within acid domains via hydrogen transfer from alkane reactants or via reactions with $\mathrm{H}_{2}$ after diffusion of alkene isomer products through such acid domains to reach Pt sites. Such selectivities to 3methylpentene isomer products from 2-methylpentane derived alkenes, which reflect the stability of methyl shift TS relative to those for TS that vary backbone length, were determined-without the use of measured selectivities-from the measured isomerization rate constants for the conversion of each hexane isomer through mechanistic interpretations of rate data. We find that acid strength influences the isomerization rates and selectivities of all skeletal isomers to a similar extent, suggesting that charge distributions are also similar among the ion-pairs that mediate each of these reactions. We conclude that the preferential formation of certain isomers reflects the different proton affinities among the gaseous analogs of their respective transition states; these differences and the extent to which deprotonation energies are recovered by interactions of such TS structures with the conjugate anion are not affected, however, by the stability of the conjugate anion and thus do not depend on the strength of the solid acid catalyst. 


\section{Experimental Methods}

\subsection{Catalyst synthesis and characterization}

$\mathrm{H}_{3} \mathrm{PW}_{12} \mathrm{O}_{40}$ (Sigma-Aldrich; reagent grade; CAS \#12501-23-4), $\mathrm{H}_{4} \mathrm{SiW}_{12} \mathrm{O}_{40}$ (Aldrich; >99.9 \%; CAS \#12027-43-9), $\mathrm{H}_{5} \mathrm{AlW}_{12} \mathrm{O}_{40}$ (as prepared in [13]), and $\mathrm{H}_{6} \mathrm{CoW}_{12} \mathrm{O}_{40}$ (prepared as in $\left.[14,15]\right)$ were supported on amorphous $\mathrm{SiO}_{2}(\mathrm{Cab}-\mathrm{O}-\mathrm{Sil}$ HS$5 ; 310 \mathrm{~m}^{2} \mathrm{~g}^{-1} ; 1.5 \mathrm{~cm}^{3} \mathrm{~g}^{-1}$ pore volume) by incipient wetness impregnation with ethanol as the solvent. $\mathrm{SiO}_{2}$ was washed three times with $1 \mathrm{M} \mathrm{HNO}_{3}$ and treated in flowing dry air (UHP Praxair; $0.5 \mathrm{~cm}^{3} \mathrm{~g}^{-1} \mathrm{~s}^{-1}$ ) at $573 \mathrm{~K}$ for $5 \mathrm{~h}$ before impregnation. Ethanolic POM solutions (ethanol, Sigma-Aldrich; >99.5\%; anhydrous) were added to pretreated $\mathrm{SiO}_{2}$ $\left(1.5 \mathrm{~cm}^{3}\right.$ solution $\left.\left[\mathrm{g} \mathrm{dry} \mathrm{SiO}_{2}\right]^{-1}\right)$ and impregnated samples were stored in closed vials for $>24 \mathrm{~h}$ before treatment in flowing dry air (UHP Praxair; $0.5 \mathrm{~cm}^{3} \mathrm{~g}^{-1} \mathrm{~s}^{-1}$ ) by heating from ambient temperature to $323 \mathrm{~K}_{\text {at }} 0.033 \mathrm{~K} \mathrm{~s}^{-1}$ and holding for $24 \mathrm{~h}$. $\mathrm{SiO}_{2}$-supported POM clusters are denoted as " $\mathrm{H}_{\mathrm{n}} \mathrm{XW} / \mathrm{SiO}_{2}$ ", where $\mathrm{n}$ is the stoichiometric number of protons per cluster and $\mathrm{X}$ is the central atom. POM concentrations in the impregnation solutions were set to give a surface density of $0.04 \mathrm{POM}\left[\mathrm{nm}-\mathrm{SiO}_{2}\right]^{-2}(\sim 5.0 \% \mathrm{wt})$ for all central atoms, unless noted otherwise. ${ }^{31} \mathrm{P}-\mathrm{MAS}-\mathrm{NMR}$ spectra of $\mathrm{H}_{3} \mathrm{PW} / \mathrm{SiO}_{2}$ (Figure S.1. in Supporting Information) confirmed that the procedures used to disperse POM clusters on $\mathrm{SiO}_{2}$ did not alter their Keggin structures. Transmission electron micrographs (Figure S.2. in Supporting Information) showed that, prior to their exposure to reaction conditions, POM clusters were present as isolated clusters or small two-dimensional oligomers on $\mathrm{SiO}_{2}$ at the surface densities used in this study.

$\mathrm{Pt} / \mathrm{Al}_{2} \mathrm{O}_{3}\left(1.5 \%\right.$ wt.), used as a co-catalyst in physical mixtures with $\mathrm{POM} / \mathrm{SiO}_{2}$ Brønsted acids, was prepared by incipient wetness impregnation of $\gamma-\mathrm{Al}_{2} \mathrm{O}_{3}$ (Sasol SBa- 
200; $193 \mathrm{~m}^{2} \mathrm{~g}^{-1}, 0.57 \mathrm{~cm}^{3} \mathrm{~g}^{-1}$ pore volume) with aqueous $\mathrm{H}_{2} \mathrm{PtCl}_{6}$ (Aldrich; CAS \#1694112-1; $0.57 \mathrm{~cm}^{3} \mathrm{~g}^{-1}$ dried $\mathrm{Al}_{2} \mathrm{O}_{3}$ ) solution. The $\gamma-\mathrm{Al}_{2} \mathrm{O}_{3}$ was treated in dry air (UHP Praxair; $0.5 \mathrm{~cm}^{3} \mathrm{~g}^{-1} \mathrm{~s}^{-1}$ ) at $923 \mathrm{~K}$ for $5 \mathrm{~h}$ prior to impregnation. The impregnated sample was treated in dry air (Praxair UHP, $0.7 \mathrm{~cm}^{3} \mathrm{~g}^{-1} \mathrm{~s}^{-1}$ ) at $383 \mathrm{~K}$ for $10 \mathrm{~h}$ before heating to $823 \mathrm{~K}_{\text {at }} 0.033 \mathrm{~K} \mathrm{~s}^{-1}$ and holding for $3 \mathrm{~h}$ in flowing dry air (Praxair UHP, $0.7 \mathrm{~cm}^{3} \mathrm{~g}^{-1} \mathrm{~s}^{-1}$ ). This sample was then treated in $\mathrm{H}_{2}$ (Praxair 99.999\%; $0.2 \mathrm{~cm}^{3} \mathrm{~g}^{-1} \mathrm{~s}^{-1}$ ) by heating to $723 \mathrm{~K}$ at $0.083 \mathrm{~K} \mathrm{~s}^{-1}$ and holding for $2 \mathrm{~h}$. After cooling to $303 \mathrm{~K}$ in He (UHP Praxair; $0.7 \mathrm{~cm}^{3} \mathrm{~g}^{-1}$ $\left.\mathrm{s}^{-1}\right)$, the $\mathrm{Pt} / \mathrm{Al}_{2} \mathrm{O}_{3}$ was treated in a dry air/He mixture $\left(2.1 \% \mathrm{~mol} \mathrm{O}_{2}, 7.9 \%\right.$ mol $\mathrm{N}_{2}, 90 \%$ mol He, $0.7 \mathrm{~cm}^{3} \mathrm{~g}^{-1} \mathrm{~s}^{-1}$ total flow) for $2 \mathrm{~h}$.

The Pt dispersion in $\mathrm{Pt} / \mathrm{Al}_{2} \mathrm{O}_{3}$ (0.92; defined as the fraction of Pt-atoms located at the surfaces of Pt particles) was determined by $\mathrm{H}_{2}$ uptakes at $298 \mathrm{~K}$ using a volumetric chemisorption unit and a 1:1 H-atom:Pts adsorption stoichiometry ( $\mathrm{Pt}_{\mathrm{s}}$, surface Pt-atom). $\mathrm{Pt} / \mathrm{Al}_{2} \mathrm{O}_{3}$ was treated in $\mathrm{H}_{2}$ (99.999\% Praxair) at $598 \mathrm{~K}$ for $1 \mathrm{~h}$ and then held under vacuum at $598 \mathrm{~K}$ for $0.5 \mathrm{~h}$ before chemisorption measurements. A $\mathrm{H}_{2}$ adsorption isotherm (99.999\% Praxair) was measured at $298 \mathrm{~K}$ from 0.1 to $50 \mathrm{kPa} \mathrm{H}_{2}$. The cell was then evacuated for $0.25 \mathrm{~h}$ at $298 \mathrm{~K}$ and a second isotherm was measured under the same conditions. The amount of chemisorbed $\mathrm{H}_{2}$ was calculated from the difference between the first and second isotherms after their respective extrapolations to zero pressure. The Pt dispersion was also determined by $\mathrm{CO}$ chemisorption at $298 \mathrm{~K}$ using similar pretreatments, a single CO (99.5\% Praxair) adsorption isotherm extrapolated to zero pressure, and by assuming a 1:1 CO:Pt $\mathrm{Pt}_{\mathrm{S}}$ adsorption stoichiometry $\left(0.78 \mathrm{Pt}_{\mathrm{S}} / \mathrm{Pt}_{\text {total }}\right)$. Their average (0.85) was used to calculate $\left(\mathrm{Pt}_{\mathrm{s}} / \mathrm{H}^{+}\right)$ratios of acid-metal mixtures. 
$\mathrm{Pt} / \mathrm{Al}_{2} \mathrm{O}_{3}$ samples were mixed with $\mathrm{POM} / \mathrm{SiO}_{2}(\mathrm{P}, \mathrm{Si}, \mathrm{Al}$, and Co central atoms) in a mortar and pestle $\left(<100 \mu \mathrm{m} \mathrm{Al}_{2} \mathrm{O}_{3}\right.$ and $\mathrm{SiO}_{2}$ particles $)$ and then pressed into wafers, crushed, and sieved to retain 125-180 $\mu$ m aggregates. The compositions of these mixtures are reported here as the ratio of $\mathrm{Pt}_{\mathrm{S}}$ (from the average dispersion from $\mathrm{H}_{2}$ and $\mathrm{CO}$ chemisorption) to accessible $\mathrm{H}^{+}$(measured by titration during catalysis; Section 3.1.1); this ratio $\left(\mathrm{Pt}_{\mathrm{S}} / \mathrm{H}^{+}\right)$was varied between 6.2 and 22.9 to determine the ratios required to achieve reactant alkane-alkene equilibrium during isomerization catalysis (Section 3.1.2.).

\subsection{Alkane isomerization rate measurements and titrations with 2,6-di-tert- butylpyridine}

2-Methylpentane (2MP), 3-methylpentane (3MP), 2,3-dimethylbutane (23DMB), and $\mathrm{n}$-hexane $(\mathrm{nH})$ isomerization rates were measured on catalyst mixtures $(0.01-0.3 \mathrm{~g})$ held within a quartz tubular flow reactor $(1.0 \mathrm{~cm}$ I.D.) using a porous quartz disk and maintained at $473 \mathrm{~K}$ by resistive heating (Watlow Series 982 controller). Temperatures were measured using a K-type thermocouple (Omega; $\pm 0.2 \mathrm{~K})$ held within an indentation at the reactor wall. Mixtures of $\mathrm{POM} / \mathrm{SiO}_{2}$ and $\mathrm{Pt} / \mathrm{Al}_{2} \mathrm{O}_{3}$ were heated to $473 \mathrm{~K}$ at $0.083 \mathrm{~K}$ $\mathrm{s}^{-1}$ in flowing $\mathrm{He}$ (UHP Praxair; $0.83 \mathrm{~cm}^{3} \mathrm{~s}^{-1}$ ) and held for $1 \mathrm{~h}$ before catalytic measurements

Liquid 2-methylpentane (Fluka; > 99.5\% analytical standard), 3-methylpentane (Fluka; > 99.5\% analytical standard), 2,3-dimethylbutane (Fluka; > $99.5 \%$ analytical standard), and n-hexane (Fluka; > 99.0 \% GC standard) reactants were evaporated into a flowing $\mathrm{He}$ (UHP Praxair) and $\mathrm{H}_{2}$ (99.999 \% Praxair) stream using a syringe pump (Cole-Palmer 74900 Series). All transfer lines were kept at $423 \mathrm{~K}$ to prevent reactants, 
products, or titrants from condensing. Flow rates of $\mathrm{He}$ and $\mathrm{H}_{2}$ were metered using electronic mass flow controllers (Porter, Model 201). Molar flow rates of alkanes, $\mathrm{H}_{2}$, and $\mathrm{He}$ were controlled to give desired $\mathrm{H}_{2}$ pressures and (alkane/ $\mathrm{H}_{2}$ ) molar ratios and to maintain low reactant conversions $(<7 \%) . \mathrm{H}_{2}$ pressures between 60 and $90 \mathrm{kPa}$ were used and (alkane/ $\mathrm{H}_{2}$ ) reactant ratios were varied between 0.01 and 0.3 (higher ratios led to significant deactivation over the course of kinetic experiments). Reactant and product concentrations in the reactor effluent were measured by gas chromatography using flame ionization detection (Agilent $6890 \mathrm{~N} \mathrm{GC} ; 50 \mathrm{~m} \mathrm{HP}-1$ column). All reactant alkanes contained one or more of the product alkanes as impurities $(<0.7 \%$ carbon selectivity); impurity concentrations were subtracted from those in the reactor effluent when calculating their formation rates. Formation rates of each product were corrected for approach to equilibrium with each reactant using:

$$
r_{\text {forward }}=r_{\text {net }}\left(1-\left(\frac{P_{\text {prod }}}{P_{\text {react }}}\right) K_{\text {prod, react }}^{-1}\right)^{-1}
$$

in which $\left(\mathrm{P}_{\text {prod }} / \mathrm{P}_{\text {react }}\right)$ is the ratio of product and reactant pressures within the reactor effluent and $\mathrm{K}_{\text {prod,react }}$ is their equilibrium constant at $473 \mathrm{~K}$ obtained from tabulated thermodynamic data [16]. Moderate catalyst deactivation $(<20 \%$ over $36 \mathrm{~h})$ occurred on some catalysts during kinetic experiments. All rates were corrected for any intervening deactivation by periodic rate measurements at reference conditions $\left(75 \mathrm{kPa} \mathrm{H}_{2}\right.$ and 1.9 $\mathrm{kPa}$ alkane).

Titration experiments were conducted by dissolving 2,6-di-tert-butylpyridine (DTBP, Aldrich; > 97\% ; CAS \#585-48-8) in liquid 2MP reactants (between $2.4 \times 10^{-2}$ and $8.6 \times 10^{-2} \% \mathrm{~mol}$ ) and evaporating this mixture into a flowing $\mathrm{H}_{2} / \mathrm{He}$ stream (UHP Praxair; $75 \% \mathrm{~mol} \mathrm{H}_{2}$ ) to give DTBP pressures between 0.45 and 2.6 Pa. Isomerization 
rates and DTBP uptakes at $473 \mathrm{~K}$ were calculated from the concentrations of $2 \mathrm{MP}$, its isomerization products, and DTBP in the reactor effluent. Isomerization rates were extrapolated to zero linearly to determine the number of DTBP molecules required to fully suppress isomerization rates. The extrapolated value was assumed to reflect the number of $\mathrm{H}^{+}$accessible during catalysis (using a $1: 1 \quad \mathrm{H}^{+}$:DTBP adsorption stoichiometry) [17].

\section{Results and Discussion}

\subsection{2-Methylpentane, 3-Methylpentane, 2,3-dimethylbutane, and n-hexane isomerization turnover rates on $\mathrm{POM} / \mathrm{SiO}_{2}$ mixtures with $\mathrm{Pt} / \mathrm{Al}_{2} \mathrm{O}_{3}$}

2-Methylpentane (2MP), 3-methylpentane (3MP), 2,3-dimethylbutane (23DMB), and n-hexane $(\mathrm{nH})$ isomerization turnover rates were measured on $\mathrm{SiO}_{2}$-supported POM clusters $\left(\mathrm{H}_{8-\mathrm{n}} \mathrm{X}^{\mathrm{n}+} \mathrm{W}_{12} \mathrm{O}_{40} / \mathrm{SiO}_{2}\right)$ with different central atoms $\left(\mathrm{X}^{\mathrm{n}+}=\mathrm{P}^{5+}, \mathrm{Si}^{4+}, \mathrm{Al}^{3+}, \mathrm{Co}^{2+}\right)$, each present as physical mixtures with $\mathrm{Pt} \mathrm{Al}_{2} \mathrm{O}_{3}$ co-catalysts. $2 \mathrm{MP}$ isomerization predominantly formed 3MP, 23DMB, and $\mathrm{nH}$ products at all conditions and on all catalysts. $2 \mathrm{MP}$ isomerization rates were much higher on these bifunctional mixtures than on $\mathrm{Pt} / \mathrm{Al}_{2} \mathrm{O}_{3}$ (by factors $>100$ ), indicating that only acid sites contribute to the formation of these isomer products. Measured 2MP isomerization selectivities to 3MP (80\% - 97\% for all conditions and catalyst mixtures) were much higher than to $23 \mathrm{DMB}$ or $\mathrm{nH}(0.1 \%$ $14.5 \%$ and $2.3 \%-5.4 \%$, respectively). Traces of 2,2-dimethylbutane (22DMB) were detected (< $0.55 \%$ carbon selectivity), but selectivities extrapolated to zero at zero conversion (varied by changing residence time; Figure S.3., Supporting Information), 
indicating that 22DMB forms only through secondary reactions of primary isomers along the catalyst bed.

On all catalyst mixtures, 3MP isomerization predominantly formed 2MP (> $85 \%$ carbon selectivity) and small amounts of 23DMB and $\mathrm{nH}$. Traces of 22DMB were also detected with 3MP reactants $(<1.1 \%$ carbon selectivity $)$ on these mixtures, but its selectivity also extrapolated to zero at short residence times (Figure S.4. in Supporting Information). $\mathrm{nH}$ isomerization at short residence times on these catalyst mixtures formed $2 \mathrm{MP}$ and $3 \mathrm{MP}$ in amounts consistent with their interconversion equilibrium $(2 \mathrm{MP} / 3 \mathrm{MP}=$ 1.4 - 1.6), much smaller concentrations of 23DMB ( $<1.0 \%$ carbon selectivity), and only traces of 22DMB $(<0.1 \%$ selectivity). 23DMB reactants on these catalyst mixtures formed predominantly $2 \mathrm{MP}$ and $3 \mathrm{MP}$ at constant ratios $(2 \mathrm{MP} / 3 \mathrm{MP}=2.0-2.3)$, moderate concentrations of 22DMB ( $~ 6 \%$ carbon selectivity), and smaller concentrations of $\mathrm{nH}$ (< $1.0 \%$ carbon selectivity) at short residence times. $2 \mathrm{MP}, 3 \mathrm{MP}$, and $\mathrm{nH}$ isomerization formed 22DMB with low selectivities that decreased monotonically with decreasing residence time, indicating that $22 \mathrm{DMB}$ forms only from 23DMB-derived alkenes, from which it can form via a single methyl shift along the backbone without the need to lengthen or shorten the length of the backbone.

These measured selectivities are consistent with elementary isomerization events that only change the number of pendant methyl groups and length of the backbone by one or none when the shifting methyl group is originally attached to tertiary, secondary, or primary carbon atoms, and not at all when the shifting methyl group is originally attached to quaternary carbon atoms. Scheme 1 depicts a reaction network for hexane isomer rearrangements that is consistent with $\mathrm{nH}$ forming only from $2 \mathrm{MP}$ and $3 \mathrm{MP}$, and 22DMB 
forming only from 23DMB. According to Scheme 1, comparisons of the absolute and relative stabilities of TS that mediate the interconversions of $2 \mathrm{MP}, 3 \mathrm{MP}, \mathrm{nH}$, and $23 \mathrm{DMB}$, require that we remove the $22 \mathrm{DMB}$ formation rate from the measured rate of conversion of $23 \mathrm{DMB}$ reactants, which reflect only the stability of the TS for $22 \mathrm{DMB}$ and 23DMB interconversion. Thus, isomerization rate constants reported here represent the rate of forming mono-branched products, which reflect the stability of the TS that mediate $23 \mathrm{DMB}$ conversion to $2 \mathrm{MP}$ and $3 \mathrm{MP}$.

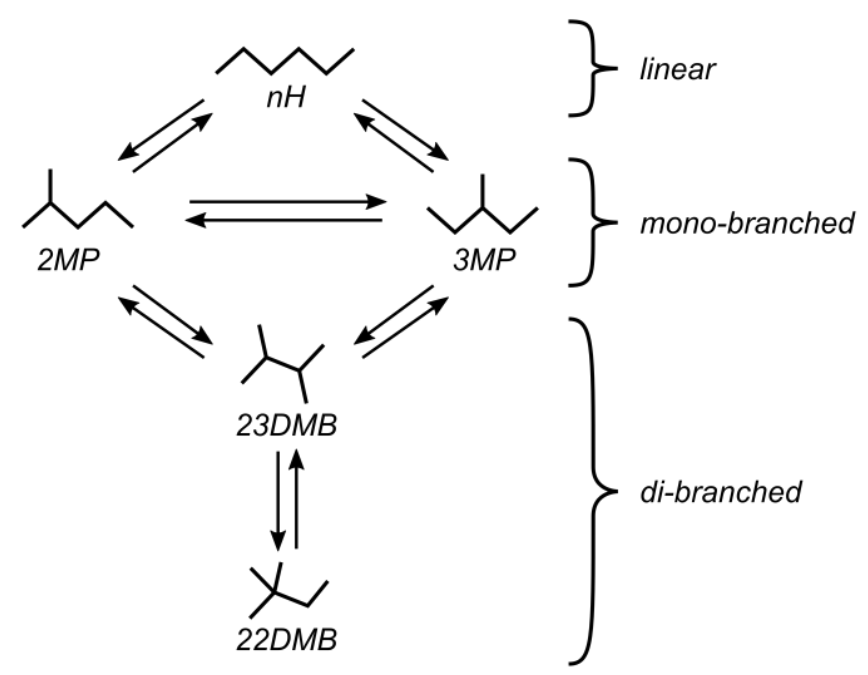

Scheme 1. Isomerization reaction network for gaseous hexane/hexene isomers on $\mathrm{POM} / \mathrm{SiO}_{2}$ mixtures with $\mathrm{Pt} / \mathrm{Al}_{2} \mathrm{O}_{3}$

\subsubsection{Titrations of protons by 2,6-di-tert-butylpyridine (DTBP) during 2-methylpentane} isomerization catalysis

2,6-di-tert-Butylpyridine (DTBP) is a selective titrant of Brønsted acid sites because it is protonated irreversibly but cannot coordinate to Lewis acid sites because of steric constraints [17]. Figure 1 shows $2 \mathrm{MP}$ isomerization rates (per POM) as a function of time or of cumulative DTBP uptake (per POM) before and during DTBP introduction, 
respectively, on $\mathrm{H}_{3} \mathrm{PW} / \mathrm{SiO}_{2}-\mathrm{Pt} / \mathrm{Al}_{2} \mathrm{O}_{3}$ and $\mathrm{H}_{4} \mathrm{SiW} / \mathrm{SiO}_{2}-\mathrm{Pt} / \mathrm{Al}_{2} \mathrm{O}_{3}$ mixtures. Isomerization rates decreased linearly with increasing DTBP uptake on both catalysts and reached undetectable levels upon titration of all protons in each sample. These data show that 2MP isomerization occurs only at Brønsted acid sites and that DTBP titrates all protons accessible to reactants. As a result, isomerization turnover rates are reported here as measured rates normalized by the number of protons $\left(\mathrm{H}^{+}\right)$titrated by DTBP in each sample (assuming a 1:1 $\mathrm{H}^{+}$:DTBP adsorption stoichiometry) during 2MP isomerization catalysis.

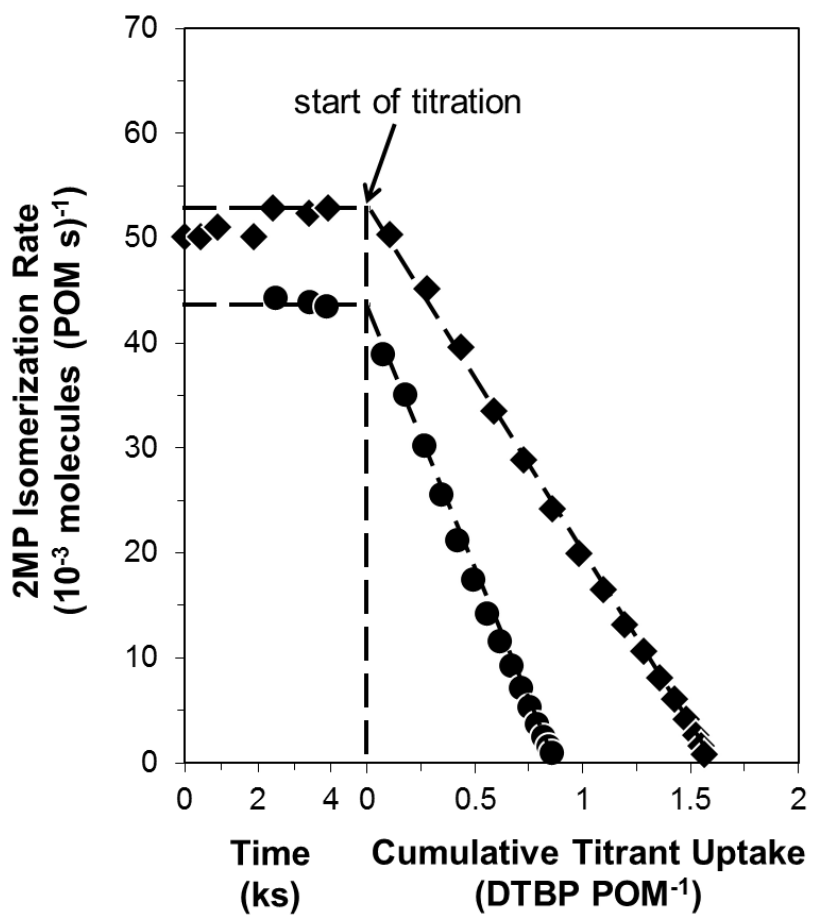

Figure 1. 2-Methylpentane isomerization rates (per POM) on (•) $\mathrm{H}_{3} \mathrm{PW} / \mathrm{SiO}_{2}-\mathrm{Pt} / \mathrm{Al}_{2} \mathrm{O}_{3} \quad\left(\mathrm{Pt}_{\mathrm{S}} / \mathrm{H}^{+}=11.7\right)$ and $(\bullet)$ $\mathrm{H}_{4} \mathrm{SiW} / \mathrm{SiO}_{2}-\mathrm{Pt} / \mathrm{Al}_{2} \mathrm{O}_{3}\left(\mathrm{Pt}_{\mathrm{S}} / \mathrm{H}^{+}=4.8\right)$ mixtures as a function of time before 2,6-di-tert-butylpyridine introduction (473 K, 1.9 $\mathrm{kPa} 2 \mathrm{MP}, 75 \mathrm{kPa} \mathrm{H}_{2}$ ) and as a function of cumulative titrant uptake (473 K, $1.9 \mathrm{kPa} 2 \mathrm{MP}, 75 \mathrm{kPa} \mathrm{H}_{2}, 0.45 \mathrm{~Pa}$ DTBP).

The number of titrated $\mathrm{H}^{+}$(per POM; Table 1) was smaller than expected from the POM stoichiometry (i.e., 8 - $\mathrm{x}$ where $\mathrm{x}$ is the valence of the central atom) by factors of 2 to 
3.5 for all POM cluster compositions. Secondary structures of POM clusters can prevent DTBP and nonpolar reactants from accessing $\mathrm{H}^{+}$located in interstitial spaces within the cubic packing of such secondary structures $[8,18]$, leading to lower DTBP uptakes than expected for isolated fully accessible POM clusters. POM features evident in TEM images of $0.04 \mathrm{POM}\left(\mathrm{nm}-\mathrm{SiO}_{2}\right)^{-2}(<2 \mathrm{~nm}$; Figure S.2. in Supporting Information) are much smaller than the secondary POM structures that would have had to exist to account for the proton counts shown in Table $1(\sim 15-20 \mathrm{~nm}$ diameters assuming POM anions with $1.2 \mathrm{~nm}$ diameters and rhombic dodecahedron secondary structures with bcc crystal structure). Substoichiometric DTBP uptakes may instead reflect intracluster POM dehydroxylation, which removes some $\mathrm{H}^{+}$and $\mathrm{POM} \mathrm{O-atoms} \mathrm{as} \mathrm{H}_{2} \mathrm{O}$, or similar reactions between $\mathrm{OH}$ groups in $\mathrm{POM}$ clusters and surface $\mathrm{OH}$ groups on $\mathrm{SiO}_{2}$ surfaces under the anhydrous conditions of isomerization catalysis [19, 20,21]. Unsupported POM clusters lose $\mathrm{H}^{+}$as water at significantly higher temperatures (623 $\mathrm{K}$ for $\mathrm{H}_{3} \mathrm{PW}_{12} \mathrm{O}_{40}$ [22]) than isomerization reaction temperatures $(473 \mathrm{~K})$, suggesting that low $\mathrm{H}^{+}$counts (Table 1) are caused instead by reactions with silanols. DTPB uptakes varied among $\mathrm{H}_{3} \mathrm{PW}_{12} \mathrm{O}_{40} / \mathrm{SiO}_{2^{-}}$ $\mathrm{Pt} / \mathrm{Al}_{2} \mathrm{O}_{3}$ mixtures containing the same $5 \mathrm{wt} \% \mathrm{H}_{3} \mathrm{PW}_{12} \mathrm{O}_{40} / \mathrm{SiO}_{2}$ catalysts (Table 1) with different amounts of $\mathrm{Pt} / \mathrm{Al}_{2} \mathrm{O}_{3}$, yet their isomerization turnover rates were identical (Figure 2), indicating that such dehydroxylation reactions do not influence the reactivity, and by inference the acid strength, of those protons which remain accessible to DTBP. Therefore, we conclude that DTBP uptakes accurately reflect the actual number of accessible Brønsted acid sites during catalysis needed to rigorously normalize rates. 


\subsubsection{Potential effects of diffusional restrictions on isomerization turnover rates and}

selectivities measured on $\mathrm{POM} / \mathrm{SiO}_{2}-\mathrm{Pt}_{\mathrm{A}} \mathrm{Al}_{2} \mathrm{O}_{3}$ mixtures

Alkane isomerization rates on bifunctional metal-acid catalysts are limited by the isomerization of alkene intermediates on Brønsted acid sites when (i) the metal function maintains alkane-alkene thermodynamic equilibrium [23] outside acid domains (defined here as the proton-containing regions devoid of metal sites) and (ii) there are no concentration gradients of reactant-derived alkenes within such acid domains. On such mixtures, transport restrictions do not corrupt measured rates of reactant depletion and calculated rate constants reflect the kinetic and thermodynamic properties of the acid sites. Next, we confirm that conditions (i) and (ii) are met for the catalyst mixtures studied here.

$\mathrm{H}_{3} \mathrm{PW} / \mathrm{SiO}_{2}-\mathrm{Pt} / \mathrm{Al}_{2} \mathrm{O}_{3}$ mixtures with $\left(\mathrm{Pt}_{\mathrm{S}} / \mathrm{H}^{+}\right)$ratios of $6.2,11.7$ and 22.9 gave similar 2MP isomerization turnover rates $\left(\right.$ per $\mathrm{H}^{+}$) at all conditions (Figure 2; $0.75-22.5$ $\mathrm{kPa} 2 \mathrm{MP}, 75 \mathrm{kPa} \mathrm{H}_{2}$ ). The isomerization turnover rates (per $\mathrm{H}^{+}$) for 3MP, 23DMB, and $\mathrm{nH}$ reactants were also unaffected by $\left(\mathrm{Pt}_{\mathrm{S}} / \mathrm{H}^{+}\right.$) ratios (Table 3; $1.9 \mathrm{kPa}$ alkane, $75 \mathrm{kPa} \mathrm{H}_{2}$ ). These results indicate that Pt sites can maintain alkane dehydrogenation-hydrogenation equilibrium for all reactants in these physical mixtures, which contain the POM acid with the highest turnover rate, thus satisfying requirement (i) above.

Reactant alkene concentration gradients within acid domains were ruled out by the similar measured 2MP, 3MP, 23DMB, and $\mathrm{nH}$ isomerization turnover rates on $\mathrm{H}_{3} \mathrm{PW} / \mathrm{SiO}_{2}-\mathrm{Pt} / \mathrm{Al}_{2} \mathrm{O}_{3}$ mixtures with very different proton densities $\left(0.03\right.$ and $0.34 \mathrm{H}^{+}$ $\left(\mathrm{nm}-\mathrm{SiO}_{2}\right)^{-2}$ ) within acid domains (Figure 2 and Table 3; $\mathrm{Pt}_{\mathrm{S}} / \mathrm{H}^{+}=10.5$ and 11.7, respectively). Any intraparticle concentration gradients of reactant alkenes would have 
been more severe on samples with higher $\mathrm{H}^{+}$densities and would have led to concomitantly lower turnover rates, because isomerization rates are nearly proportional to reactant alkene concentrations at the conditions of these experiments [24]. All rate data used to determine kinetic parameters on $\mathrm{H}_{3} \mathrm{PW}$ were obtained on samples with $0.03 \mathrm{H}^{+}$ $\mathrm{nm}^{-2}$ acid site densities and a $\left(\mathrm{Pt}_{\mathrm{s}} / \mathrm{H}^{+}\right)$ratio of 11.7 to ensure strict kinetic control and the absence of any diffusional corruptions of measured rates and rate constants.

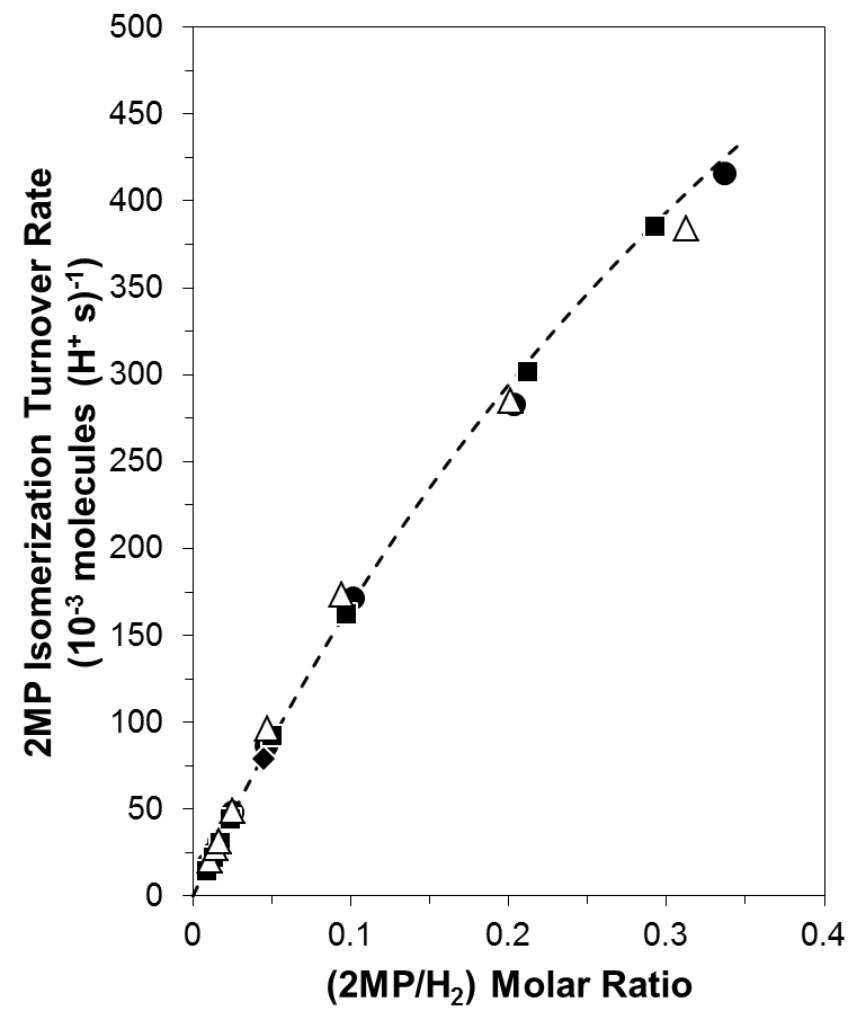

Figure 2. 2-Methylpentane isomerization turnover rates as a function of $\left(2 \mathrm{MP} / \mathrm{H}_{2}\right)$ ratios on $\mathrm{H}_{3} \mathrm{PW} / \mathrm{SiO}_{2}-\mathrm{Pt} / \mathrm{Al}_{2} \mathrm{O}_{3}$ mixtures with $(\diamond) 0.03 \mathrm{H}^{+}\left[\mathrm{nm}-\mathrm{SiO}_{2}\right]^{-2}$ and $\mathrm{Pt}_{\mathrm{S}} / \mathrm{H}^{+}=6.2,(\bullet) 0.03 \mathrm{H}^{+}$ $\left[\mathrm{nm}-\mathrm{SiO}_{2}\right]^{-2}$ and $\mathrm{Pt}_{\mathrm{S}} / \mathrm{H}^{+}=11.7,(\triangle) 0.04 \mathrm{H}^{+}\left[\mathrm{nm}-\mathrm{SiO}_{2}\right]^{-2}$ and $\mathrm{Pt}_{\mathrm{S}} / \mathrm{H}^{+}=22.9$, and $(\square) 0.34 \mathrm{H}^{+}\left[\mathrm{nm}-\mathrm{SiO}_{2}\right]^{-2}$ and $\mathrm{Pt}_{\mathrm{S}} / \mathrm{H}^{+}=10.5$ (reaction conditions: $473 \mathrm{~K}, 0.5-25 \mathrm{kPa} 2 \mathrm{MP}, 75 \mathrm{kPa} \mathrm{H}_{2}$ ). Dashed lines represent the regression of the data to the functional form of Eq. 4.

Bifunctional mixtures with $\left(\mathrm{Pt}_{\mathrm{S}} / \mathrm{H}^{+}\right)$ratios smaller than 11.7 were used for the other POM acids $\left(\mathrm{Pt}_{\mathrm{S}} / \mathrm{H}^{+}=4.8,5.0\right.$, and 5.9 for $\mathrm{H}_{4} \mathrm{SiW} / \mathrm{SiO}_{2}-\mathrm{Pt} / \mathrm{Al}_{2} \mathrm{O}_{3}, \mathrm{H}_{5} \mathrm{AlW} / \mathrm{SiO}_{2^{-}}$ 
$\mathrm{Pt} / \mathrm{Al}_{2} \mathrm{O}_{3}$, and $\mathrm{H}_{6} \mathrm{CoW} / \mathrm{SiO}_{2}-\mathrm{Pt} / \mathrm{Al}_{2} \mathrm{O}_{3}$ mixtures, respectively), which have lower isomerization turnover rates than $\mathrm{H}_{3} \mathrm{PW} / \mathrm{SiO}_{2}-\mathrm{Pt}_{/} / \mathrm{Al}_{2} \mathrm{O}_{3}$ mixtures (Figure 4). Such ratios were chosen to avoid any contributions to rates from Pt-catalyzed isomerization reactions (Section 3.1). These mixtures have $\left(\mathrm{Pt}_{\mathrm{s}} / \mathrm{H}^{+}\right)$ratios similar to (and isomerization turnover rates lower than) the $\mathrm{H}_{3} \mathrm{PW} / \mathrm{SiO}_{2}-\mathrm{Pt} / \mathrm{Al}_{2} \mathrm{O}_{3}$ mixture with a $\left(\mathrm{Pt}_{\mathrm{s}} / \mathrm{H}^{+}\right)$ratio of 6.2 , for which such ratios were sufficient to maintain alkane dehydrogenation-hydrogenation equilibrium for 2MP reactants, suggesting that the metal function in these samples are also sufficient to maintain alkane-alkene equilibrium outside acid domains. Transport restrictions within acid domains for reactant alkenes would have been less severe for these other POM acids supported with $0.04 \mathrm{POM}\left(\mathrm{nm}-\mathrm{SiO}_{2}\right)^{-2}$ surface densities (which were used for kinetic experiments) than for the $\mathrm{H}_{3} \mathrm{PW} / \mathrm{SiO}_{2}$ sample with a $0.20 \mathrm{POM}$ $\left(\mathrm{nm}-\mathrm{SiO}_{2}\right)^{-2}$ surface density, because they have much lower isomerization rates than the $\mathrm{H}_{3} \mathrm{PW} / \mathrm{SiO}_{2}$ sample when normalized by the pellet volume of the silica support ( $\sim 8-$ 140 fold), yet similar diffusion rates because of the similar size and porous structure of the silica domains that contain the acid sites. Thus, isomerization turnover rates measured on these $\mathrm{H}_{4} \mathrm{SiW} / \mathrm{SiO}_{2}-\mathrm{Pt} / \mathrm{Al}_{2} \mathrm{O}_{3}, \mathrm{H}_{5} \mathrm{AlW} / \mathrm{SiO}_{2}-\mathrm{Pt} / \mathrm{Al}_{2} \mathrm{O}_{3}$, and $\mathrm{H}_{6} \mathrm{CoW} / \mathrm{SiO}_{2}-\mathrm{Pt} / \mathrm{Al}_{2} \mathrm{O}_{3}$ mixtures are not corrupted by transport restrictions.

Measured alkane isomerization selectivities on bifunctional metal-acid catalysts reflect the relative rates of product formation from reactant alkenes after only a single sojourn at an acid site only when rates of secondary interconversions of alkene products are much lower than their respective hydrogenation rates, either locally within acid domains via hydrogen transfer from alkane reactants or via reactions with $\mathrm{H}_{2}$ after their diffusion through such acid domains to reach Pt sites. Only on such mixtures, transport 
restrictions would not corrupt measured selectivities and calculated rate constants for individual product formation would rigorously reflect the kinetic and thermodynamic properties of the isomerization TS that mediates each respective formation reactions. Selectivities measured on such mixtures at differential conditions are expected to be independent of rates of product alkene hydrogenation and, consequently, reactant alkane pressure. Figure 3 shows $2 \mathrm{MP}$ isomerization selectivities to $23 \mathrm{DMB}\left(\mathrm{S}_{\text {meas,23 }}\right)$ and $\mathrm{nH}$ ( $\mathrm{S}_{\text {meas,nH}}$ ) products as a function of $2 \mathrm{MP}$ pressure and $75 \mathrm{kPa} \mathrm{H}$ on $\mathrm{H}_{3} \mathrm{PW} / \mathrm{SiO}_{2}-\mathrm{Pt}_{/} / \mathrm{Al}_{2} \mathrm{O}_{3}$ mixtures with very different acid site densities $\left(0.03\right.$ and $\left.0.34 \mathrm{H}^{+}\left(\mathrm{nm}-\mathrm{SiO}_{2}\right)^{-2}\right) . \mathrm{S}_{\text {meas, } 23}$ and $\mathrm{S}_{\text {meas,nH}}$ values decrease with increasing $2 \mathrm{MP}$ pressure on these samples suggesting they depend, to some extent, on rates of product alkene hydrogenation via hydride transfer from alkane reactants. Increasing 2MP pressure increases rates of hydrogenation locally within acid domains, decreasing the concentration of product alkenes in such acid domains and, concomitantly, rates of secondary interconversions of alkene products. $\mathrm{S}_{\text {meas,nH }}$ values in Figure 3 appear to approach constant values at high 2MP pressures (>10 $\mathrm{kPa}$ ) suggesting that at such high 2MP pressures increasing rates of hydrogenation locally within acid domains is not effective at changing the net rate of secondary interconversions among 3MP and nH derived alkene products. Decreasing the acid site density of the $\mathrm{H}_{3} \mathrm{PW} / \mathrm{SiO}_{2}-\mathrm{Pt} / \mathrm{Al}_{2} \mathrm{O}_{3}$ mixtures, which decrease rates of secondary interconversions and hydrogenation via hydride transfer from alkane reactants within such domains but not the rates of diffusion of product alkenes through acid domains, gave higher $\mathrm{S}_{\text {meas,nH }}$ values (by 1.4 factors) at high $2 \mathrm{MP}$ pressures (>10 $\mathrm{kPa}$ in Figure 3). These data indicate that transport restrictions indeed influence measured selectivities on these samples for the range of $2 \mathrm{MP}$ and $\mathrm{H}_{2}$ pressures in Figure 3 (including $2 \mathrm{MP}$ 
pressures $>10 \mathrm{kPa}$ ); as a result, secondary interconversions of alkene products at these conditions occur at rates similar to their hydrogenation, both locally within acid domains via hydrogen transfer from alkane reactants and via reactions with $\mathrm{H}_{2}$ after their diffusion through such acid domains to reach Pt sites. In such cases, rates and selectivities for isomerization reactions to individual primary products (defined as those formed from reactant alkenes in one surface sojourn) cannot be inferred directly from measured selectivities. These constraints preclude the determination of such individual product formation rates for most of the isomer products formed; as we show in Section 3.1.3, such formation rates and, as a result, selectivities for 3-methylpentene formation as a primary product from 2-methylpentene can be determined explicitly for any given catalyst mixture from measured isomerization turnover rates for 2MP, 3MP, 23DMB, and $\mathrm{nH}$ reactants. Next, such isomerization turnover rates measured on $\mathrm{H}_{3} \mathrm{PW} / \mathrm{SiO}_{2}-\mathrm{Pt}_{/} / \mathrm{Al}_{2} \mathrm{O}_{3}$, $\mathrm{H}_{4} \mathrm{SiW} / \mathrm{SiO}_{2}-\mathrm{Pt} / \mathrm{Al}_{2} \mathrm{O}_{3}, \mathrm{H}_{5} \mathrm{AlW} / \mathrm{SiO}_{2}-\mathrm{Pt} / \mathrm{Al}_{2} \mathrm{O}_{3}$, and $\mathrm{H}_{6} \mathrm{CoW} / \mathrm{SiO}_{2}-\mathrm{Pt} / \mathrm{Al}_{2} \mathrm{O}_{3}$ mixtures are interpreted mechanistically. 


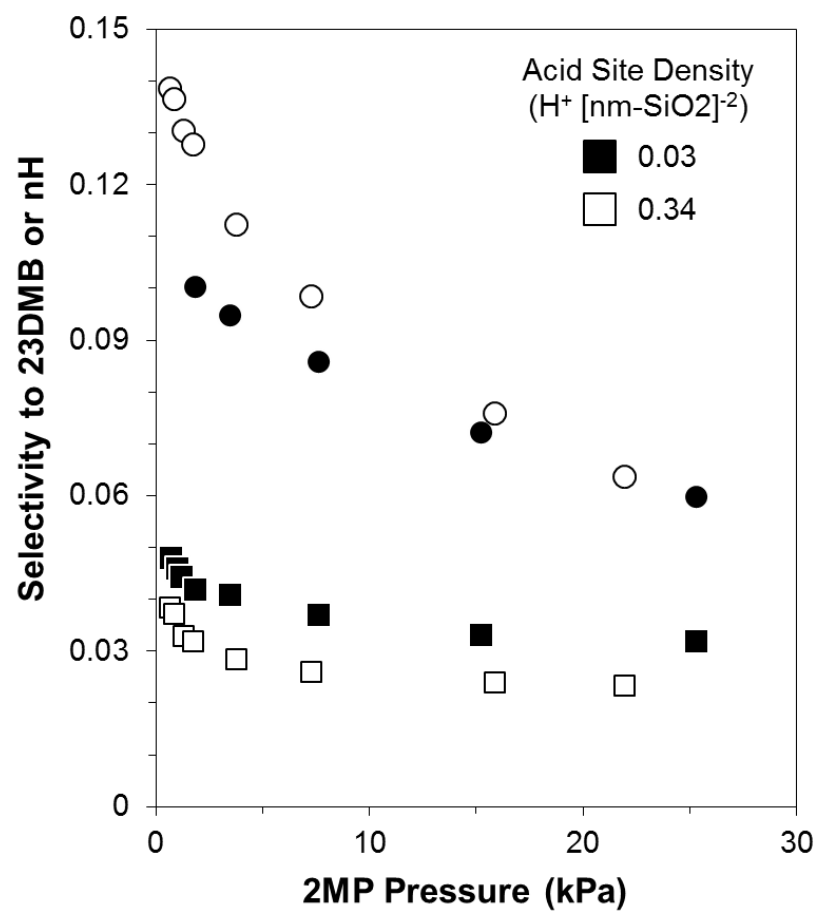

Figure 3. Isomerization selectivities to 23DMB $(\bullet)$ and $\mathrm{nH}$ (匹) products for $2 \mathrm{MP}$ reactants on $\mathrm{H}_{3} \mathrm{PW} / \mathrm{SiO}_{2}-\mathrm{Pt} / \mathrm{Al}_{2} \mathrm{O}_{3}$ $\left(\mathrm{Pt}_{\mathrm{S}} / \mathrm{H}^{+}=10.5-11.7 ; \mathrm{H}^{+}\left[\mathrm{nm}-\mathrm{SiO}_{2}\right]^{-2}=0.03-0.34\right)$ as a function of $2 \mathrm{MP}$ pressure $(473 \mathrm{~K}, 0.7-25 \mathrm{kPa} 2 \mathrm{MP}, 75 \mathrm{kPa}$ $\mathrm{H}_{2}$ ).

3.1.3. Mechanistic interpretation of isomerization turnover rate data for $\mathrm{POM} / \mathrm{SiO}_{2}-$ $\mathrm{Pt} / \mathrm{Al}_{2} \mathrm{O}_{3}$ mixtures

Figure 4a shows 2MP isomerization turnover rates $\left(\right.$ per $\mathrm{H}^{+}$) as a function of $\left(2 \mathrm{MP} / \mathrm{H}_{2}\right)$ ratio (a surrogate for the concentration of the alkene regioisomers with the 2methyl backbone in equilibrium with $2 \mathrm{MP}$ reactants) on $\mathrm{POM} / \mathrm{SiO}_{2}-\mathrm{Pt} / \mathrm{Al}_{2} \mathrm{O}_{3}$ mixtures with $\mathrm{P}, \mathrm{Si}, \mathrm{Al}$, and $\mathrm{Co}$ central atoms $\left(\left(\mathrm{Pt}_{\mathrm{s}} / \mathrm{H}^{+}\right)=4.8-11.7\right) .2 \mathrm{MP}$ isomerization turnover rates (at a given reaction condition) increased as the valence of the POM central atom decreased. Turnover rates also increased with increasing $\left(2 \mathrm{MP} / \mathrm{H}_{2}\right)$ ratios on each sample, linearly at first and then more gradually at higher reactant ratios (Figure 4a). 2MP isomerization rates depend only on $\left(2 \mathrm{MP} / \mathrm{H}_{2}\right)$ ratios and not on the individual values of 
the $2 \mathrm{MP}$ or $\mathrm{H}_{2}$ pressures $\left(60-90 \mathrm{kPa} \mathrm{H}\right.$ ) used to obtain these ratios on all $\mathrm{POM} / \mathrm{SiO}_{2}$ $\mathrm{Pt} / \mathrm{Al}_{2} \mathrm{O}_{3}$ mixtures.

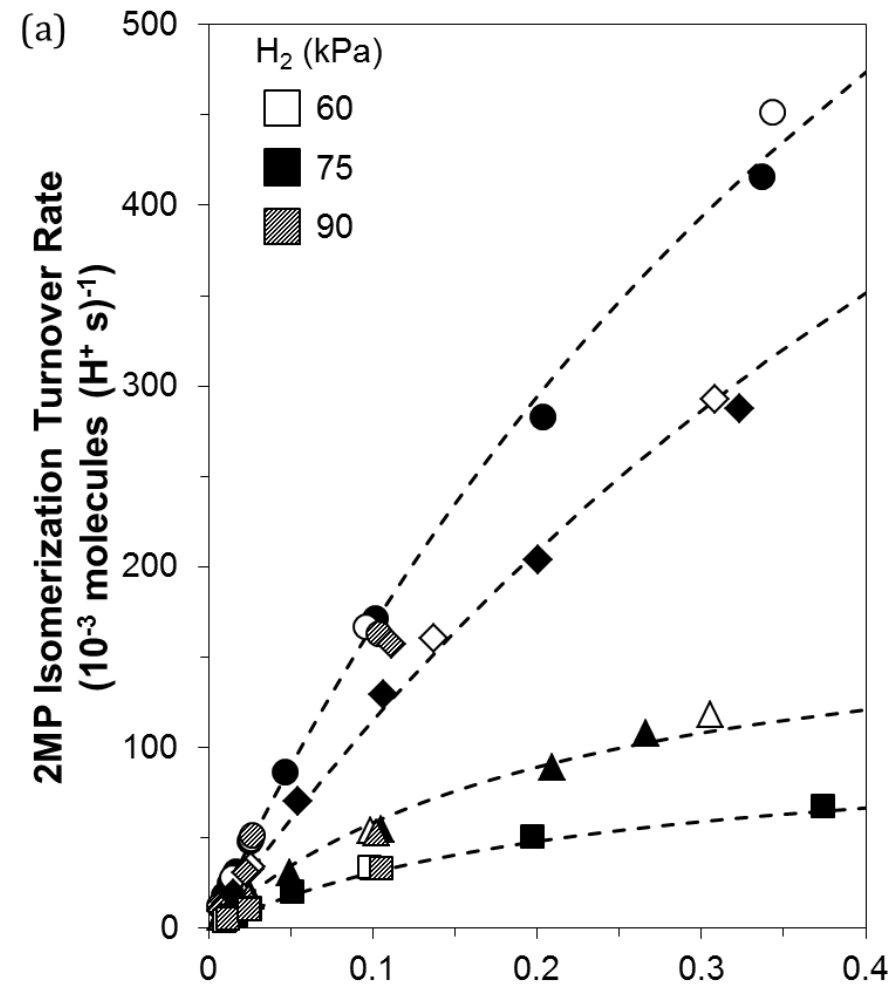

$\left(2 \mathrm{MP} / \mathrm{H}_{2}\right)$ Molar Ratio

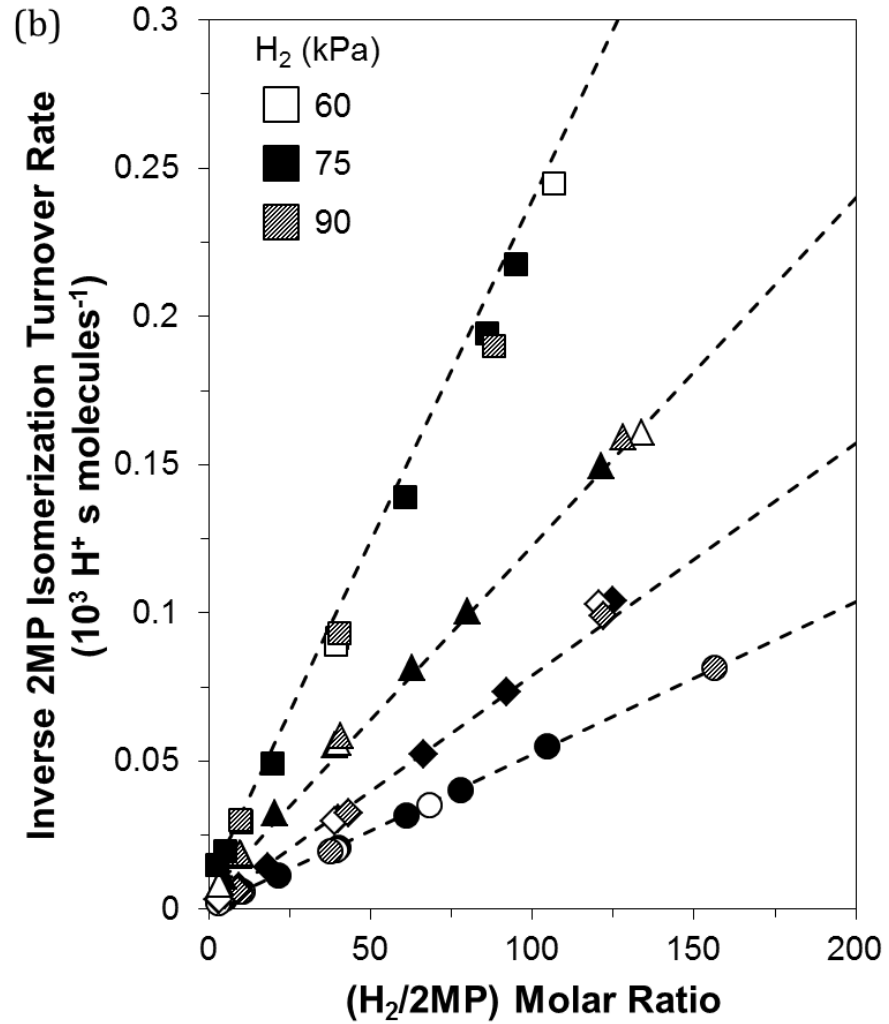

Figure 4. (a) 2-Methylpentane isomerization turnover rates as functions of the $\left(2 \mathrm{MP} / \mathrm{H}_{2}\right)$ ratio and (b) inverse 2 methylpentane isomerization turnover rates as a function of the $\left(\mathrm{H}_{2} / 2 \mathrm{MP}\right)$ ratio on mixtures of $\mathrm{Pt}_{2} / \mathrm{Al}_{2} \mathrm{O}_{3}$ with (O) $\mathrm{H}_{3} \mathrm{PW} / \mathrm{SiO}_{2}\left(\mathrm{Pt}_{\mathrm{S}} / \mathrm{H}^{+}=11.7\right),(\diamond) \mathrm{H}_{4} \mathrm{SiW} / \mathrm{SiO}_{2}\left(\mathrm{Pt}_{\mathrm{S}} / \mathrm{H}^{+}=4.8\right),(\boldsymbol{\Delta}) \mathrm{H}_{5} \mathrm{AlW} / \mathrm{SiO}_{2}\left(\mathrm{Pt}_{\mathrm{S}} / \mathrm{H}^{+}=5.0\right)$, and (品 $\mathrm{H}_{6} \mathrm{CoW} / \mathrm{SiO}_{2}\left(\mathrm{Pt}_{\mathrm{S}} / \mathrm{H}^{+}=5.9\right)$ (reaction conditions: $\left.473 \mathrm{~K}, 0.5-25 \mathrm{kPa} 2 \mathrm{MP}, 60-90 \mathrm{kPa} \mathrm{H}_{2}\right)$. Dashed lines represent the regression of the data to the functional form of Eq. 4.

The elementary steps in Scheme 2 may be used to derive a rate equation consistent with these measured effects of $\left(2 \mathrm{MP} / \mathrm{H}_{2}\right)$ ratios on isomerization rates, as shown previously for other bifunctional isomerization catalysts $[8,23,25]$. Pt sites equilibrate 2MP with all 2-methylpentene regioisomers (Scheme 2, Step 1 illustrated for the case of 2-methylpent-2-ene); as a result, alkene pressures are proportional to $\left(2 \mathrm{MP} / \mathrm{H}_{2}\right)$ ratios and to their respective dehydrogenation equilibrium constants $\left(\mathrm{K}_{\mathrm{dehy}, 2}\right)$. Quasi-equilibrated protonation of 2-methylpentene isomers at acid sites forms adsorbed 
2-methylpentoxide isomers with backbone attachments to surfaces at locations prescribed by their relative thermodynamic stability (Scheme 2, Step 2 shown for 2-methylpent-2ene and 2-methypent-3-oxide). Adsorbed 2-methylpentoxides then isomerize in irreversible steps to alkoxides with a different backbone structure (Scheme 2, Step 3 for the case of 3-methylpent-2-oxide). These backbone rearrangements are mediated by cationic TS that resemble cyclopropyl carbenium ions (or cyclobutyl carbenium ions for interconversions of 3-methylpentoxides and 2,3-dimethylpentoxides) in which C-C bonds (and C-H bonds, for cyclopropyl carbenium ion TS that change the number of pendant methyls) bonds cleave and form in concerted steps [26-30]. Product alkoxides either deprotonate to form their gaseous alkenes (Scheme 2, Step 4 shown for 3-methylpent-2ene) or hydrogenate via hydrogen transfer from $2 \mathrm{MP}$ to form their respective gaseous alkane isomer and a 2-methylpentoxide (Scheme 2, Step 5 shown for 3-methylpent-2oxide and 2-methylpent-3-oxide). Gaseous alkene products may re-protonate at acid sites (Scheme 2, Step 4) or diffuse to Pt sites and undergo hydrogenation reactions with $\mathrm{H}_{2}$ to form the respective gaseous alkane isomer (Scheme 2, Step 6 shown for 3MP). Alkenes (and alkoxides) with a given backbone but different double-bond positions can be rigorously treated in all kinetic analyses as a lumped chemical pseudo-species, because of their rapid interconversions. These alkene (and alkoxide) pseudo-species are denoted henceforth by the superscript symbol "=" (and “*”) without specifying the position of the double bond in the gaseous alkene and of the surface attachment in the alkoxides (e.g., 2methylpentane, 2-methylpentene isomers, and 2-methylpentoxide isomers are denoted as $2 \mathrm{MP}, 2 \mathrm{MP}^{=}$, and $2 \mathrm{MP}^{*}$ respectively). 
(1)

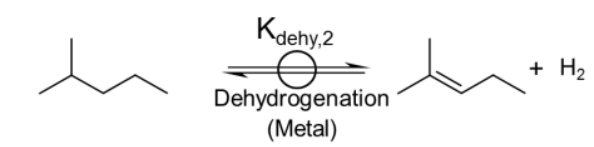

(2)

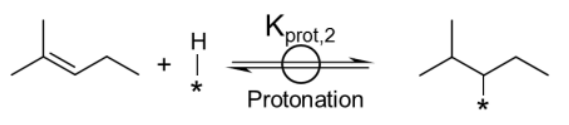

(3)

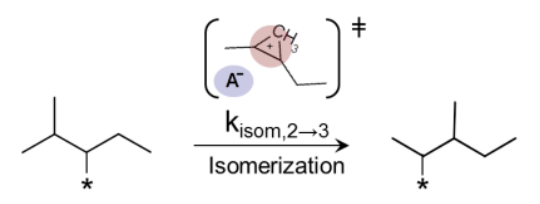

(4)

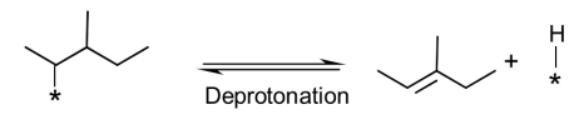

(5)

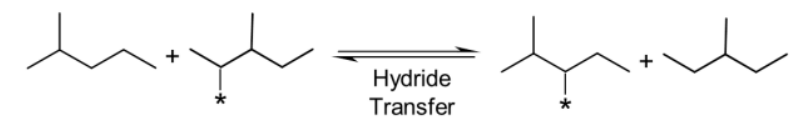

(6)

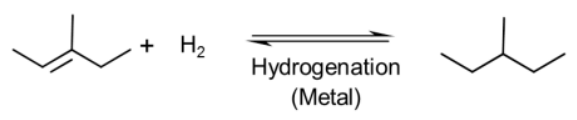

Scheme 2. Elementary steps and chemical reactions involved in 2methylpentane isomerization on metal-acid mixtures that establish 2methylpentane/2-methylpentene equilibrium. Chemical reactions are shown for the (de)hydrogenation on metal sites $\left(\mathrm{Pt} / \mathrm{Al}_{2} \mathrm{O}_{3}\right)$ and elementary steps for acid-catalyzed routes on $\mathrm{H}_{8-\mathrm{n}} \mathrm{X}^{\mathrm{n+}} \mathrm{W}_{12} \mathrm{O}_{40} / \mathrm{SiO}_{2}\left(\mathrm{X}=\mathrm{P}^{5+}, \mathrm{Si}^{4+}, \mathrm{Al}^{3+}, \mathrm{Co}^{2+}\right)$. Steps 3 - 6 are illustrated using 3-methylpentane as the product, but analogous steps are involved in 2,3-dimethylbutane and n-hexane formation. Bonds to the Brønsted active site are denoted as "*” in molecular structures.

The assumptions of pseudo-steady-state for alkoxides and of equilibrated hydrogenation-dehydrogenation and protonation-deprotonation steps, taken together with $2 \mathrm{MP}^{*}$ and $\mathrm{H}^{+}$as the most abundant surface intermediates (MASI) and irreversible skeletal isomerization of $2 \mathrm{MP}^{*}$, lead to a rate equation for $2 \mathrm{MP}$ isomerization to each alkane product isomer " $\mathrm{P}$ " $\left(\mathrm{r}_{\text {isom, } 2 \rightarrow \mathrm{P}} ; \mathrm{P}=3 \mathrm{MP}(3), 23 \mathrm{DMB}(23)\right.$, or $\mathrm{nH}$; full derivation in Section S.3. of Supporting Information): 


$$
\frac{r_{i s o m, 2 \rightarrow P}}{\left[H^{+}\right]}=\frac{k_{\text {isom }, 2 \rightarrow P} K_{\text {prot }, 2} K_{\text {dehy }, 2}\left(\frac{2 M P}{H_{2}}\right)}{1+K_{\text {prot }, 2} K_{\text {dehy }, 2}\left(\frac{2 M P}{H_{2}}\right)}
$$

Here, $\left[\mathrm{H}^{+}\right]$is the number of accessible $\mathrm{H}^{+}$(from DTBP titration data, Section 3.1.1), $\mathrm{K}_{\text {prot,2}}$ is the equilibrium constant for $2 \mathrm{MP}^{=}$protonation to $2 \mathrm{MP}^{*}$ (2-methylpent-3-oxide used as example in Scheme 2), and $\mathrm{k}_{\mathrm{isom}, 2 \rightarrow \mathrm{P}}$ is the alkoxide isomerization rate constant that forms product "P". The first and second terms in the denominator of Eq. 2 reflect the relative numbers of active sites present as unoccupied $\mathrm{H}^{+}$and $2 \mathrm{MP}^{*}$, respectively; the coverage by product-derived alkoxides is much smaller than that by $2 \mathrm{MP}^{*}$, because of the low concentrations of product-alkenes at the low conversions of these experiments. All product formation rate equations have the same denominator (with terms only for $\mathrm{H}^{+}$ and 2MP* species) because all products form on the same Brønsted acid sites. The sum of rate equations similar in functional form to Eq. 2 but for each 3MP, 23DMB, and $\mathrm{nH}$ product gives an equation for the total $2 \mathrm{MP}$ isomerization rate $\left(\mathrm{r}_{\mathrm{isom}, 2}\right)$ at $2 \mathrm{MP}-2 \mathrm{MP}^{=}$ equilibrium:

$$
\frac{r_{\text {isom }, 2}}{\left[H^{+}\right]}=\frac{k_{\text {isom }, 2} K_{\text {prot }, 2} K_{\text {dehy }, 2}\left(\frac{2 M P}{H_{2}}\right)}{1+K_{p r o t, 2} K_{\text {dehy }, 2}\left(\frac{2 M P}{H_{2}}\right)}
$$

in terms of the sum of the individual rate constants for the isomerization to form each product

$$
k_{i s o m, 2}=k_{i s o m, 2 \rightarrow 3}+k_{i s o m, 2 \rightarrow 23}+k_{i s o m, 2 \rightarrow n H}
$$

$\mathrm{K}_{\text {prot }, 2} \mathrm{~K}_{\text {dehy,2 }}$ values in Eq. $3 \mathrm{a}$ are independent of the product being formed because all isomerization events originate from the same pool of equilibrated surface alkoxide 
species (2MP*). These equations describe the rate data shown in Figure 2, because $2 \mathrm{MP}^{=}$ concentrations remain at equilibrium with $2 \mathrm{MP}$ reactants at all acid sites throughout the reactor.

2MP isomerization rates that depend inversely on $\left(\mathrm{H}_{2} / 2 \mathrm{MP}\right)$ ratios (Figure $\left.4 \mathrm{~b}\right)$ and lie along a single curve at all $\mathrm{H}_{2}$ pressures $\left(60-90 \mathrm{kPa} \mathrm{H}_{2}\right.$; Figures $4 \mathrm{a}$ and $\left.4 \mathrm{~b}\right)$ are consistent with the form of Eq. 3a and with 2MP-2MP $=$ equilibration:

$$
\left(\frac{r_{\text {isom }, 2}}{\left[H^{+}\right]}\right)^{-1}=\frac{1}{k_{\text {isom }, 2} K_{\text {prot }, 2} K_{\text {dehy }, 2}}\left(\frac{H_{2}}{2 M P}\right)+\frac{1}{k_{\text {isom }, 2}}
$$

The slope and intercept of linear rate data shown in Figure $4 \mathrm{~b}$, therefore, reflect the values of the kinetic and thermodynamic parameters in Eq. 4. The values of the firstorder rate constant for alkene isomerization $\left(\mathrm{k}_{\mathrm{isom}, 2} \mathrm{~K}_{\mathrm{prot}, 2}\right)$ were regressed from the data in Figure $4 \mathrm{~b}$ for each POM acid to the functional form of Eq. 4 using thermodynamic data [16,31] for the gas phase equilibrium constant for alkane-alkene equilibration $\left(\mathrm{K}_{\mathrm{dehy}, 2}=\right.$ $1.10 \mathrm{~Pa}$ at $473 \mathrm{~K}$ ); their values are shown in Table 2. The zero-order rate constant for alkene isomerization $\left(\mathrm{k}_{\mathrm{isom}, 2}\right)$ and the equilibrium constant for the formation of alkoxide species at acid sites from gaseous alkenes $\left(\mathrm{K}_{\text {prot, } 2)}\right)$ were regressed from the data in Figure 4a to the functional form of Eq. 3a using the determined $\mathrm{k}_{\text {isom, } 2} \mathrm{~K}_{\text {prot,2 }}$ value for each POM acid. These rate data provide accurate values for $\mathrm{k}_{\mathrm{isom}, 2} \mathrm{~K}_{\text {prot }, 2}$, but not for $\mathrm{k}_{\mathrm{isom}, 2}$ (or $\mathrm{K}_{\text {prot }, 2}$ ) (e.g., linear regressions of rate data measured on POM clusters give errors for $\mathrm{k}_{\mathrm{isom}, 2} \mathrm{~K}_{\mathrm{prot}, 2}$ $< \pm 0.8 \%$ of the reported values, but up to $\pm 120 \%$ of the values reported for $\left.\mathrm{k}_{\mathrm{isom}, 2}\right)$. The form and mechanistic interpretation of Eq. 4 indicate that accurate $\mathrm{k}_{\text {isom, }, 2}$ estimates would require $\left(\mathrm{H}_{2} / 2 \mathrm{MP}\right)$ ratios that cause detectable contributions from its intercept and, as a result, lead to kinetically-detectable alkoxide coverages (the second term in the denominator of Eq. 3b). Such small $\left(\mathrm{H}_{2} / 2 \mathrm{MP}\right)$ ratios favor bimolecular alkene-alkoxide 
oligomerization reactions that can form unreactive oligomers that bind irreversibly to acid sites leading to catalyst deactivation. As a result, regressions were limited in this study to $\left(2 \mathrm{MP} / \mathrm{H}_{2}\right)$ ratios below $\sim 0.1$ (i.e., when the second term is much smaller than unity in the denominator of Eq. 3a) and become less accurate at higher $\left(2 \mathrm{MP} / \mathrm{H}_{2}\right)$ ratios (dashed curves in Figure 4a).

Figure 5a shows 2MP, 3MP, 23DMB, and $\mathrm{nH}$ total isomerization turnover rates (normalized by $\mathrm{H}^{+}$titrated with DTBP, Table 1) as a function of (alkane/ $\mathrm{H}_{2}$ ) ratios on $\mathrm{H}_{3} \mathrm{PW} / \mathrm{SiO}_{2}-\mathrm{Pt} / \mathrm{Al}_{2} \mathrm{O}_{3}$ mixtures with $0.03 \mathrm{H}^{+} \mathrm{nm}^{-2}$ surface density and $11.7\left(\mathrm{Pt}_{\mathrm{S}} / \mathrm{H}^{+}\right)$ratios. Turnover rates increased with increasing (alkane/ $\mathrm{H}_{2}$ ) ratios for all reactants, linearly at first and then more gradually at higher reactant ratios (Figure 4a). Isomerization turnover rates at different $\mathrm{H}_{2}$ pressures lie along a single curve for each reactant (Figures 5a and $5 \mathrm{~b}$ ), as expected from alkane-alkene equilibration (as in the case of 2MP reactants; Fig. $3 \mathrm{a}$ and $3 \mathrm{~b}$ ). These data show that the elementary steps in Scheme 2 accurately represent the isomerization pathways for all hexane isomers used as reactants and that all rate data can be described by:

$$
\frac{r_{\text {isom }, R}}{\left[H^{+}\right]}=\frac{k_{\text {isom }, R} K_{\text {prot }, R} K_{\text {dehy }, R}\left(\frac{[R]}{H_{2}}\right)}{1+K_{\text {prot }, R} K_{\text {dehy }, R}\left(\frac{[R]}{H_{2}}\right)}
$$

Here, $K_{\text {dehy, } R}$ is the dehydrogenation equilibrium constant for reactant " $R$ " $(R=2 M P(2)$, 3MP (3), 23DMB (23), or $\mathrm{nH}(\mathrm{nH})$ ) calculated from tabulated thermodynamic data [31] $\left(\mathrm{K}_{\text {dehy }, 3}=1.15 \mathrm{~Pa}, \mathrm{~K}_{\text {dehy }, 23}=1.67 \mathrm{~Pa}\right.$, and $\mathrm{K}_{\text {dehy }, \mathrm{nH}}=0.28 \mathrm{~Pa}$ at $\left.473 \mathrm{~K}\right) . \mathrm{K}_{\text {prot }, \mathrm{R}}$ is the equilibrium constant for the formation of a given alkoxide regioisomer group ([ $\left.\mathrm{R}^{*}\right]$ ) from the equilibrated alkene lump, $\left[R^{=}\right]$, for reactant " $R$ "; $k_{i s o m, R}$ is the isomerization rate 
constant for the total conversion of $\left[\mathrm{R}^{*}\right]$ to all isomer products. The dashed curves in Figures $5 \mathrm{a}$ and $5 \mathrm{~b}$ represent the regression of these data to Eq. 5 using the method described above for $2 \mathrm{MP}$ reactants to obtain $\mathrm{k}_{\mathrm{isom}, \mathrm{R}} \mathrm{K}_{\text {prot, } \mathrm{R}}, \mathrm{K}_{\text {prot } \mathrm{R}}$, and $\mathrm{K}_{\text {dehy, } \mathrm{R}}$ values. As in the case of $2 \mathrm{MP}$ reactants, $\mathrm{k}_{\mathrm{isom}, \mathrm{R}} \mathrm{K}_{\mathrm{prot}, \mathrm{R}}$ values for $3 \mathrm{MP}, 23 \mathrm{DMB}$, and $\mathrm{nH}$ reactants can be determined more accurately than $\mathrm{k}_{\mathrm{isom}, \mathrm{R}}$ values (or $\mathrm{K}_{\text {prot,R}}$ ) (e.g., linear regressions of data in Figure $5 \mathrm{~b}$ give errors for $\mathrm{k}_{\mathrm{isom}, \mathrm{R}} \mathrm{K}_{\mathrm{prot}, \mathrm{R}}< \pm 0.9 \%$ of the reported values, but errors for $\mathrm{k}_{\text {isom, } \mathrm{R}}$ up to $\pm 430 \%$ of the reported values). The $\mathrm{k}_{\text {isom, } \mathrm{R}} \mathrm{K}_{\text {prot, } \mathrm{R}}$ values for $3 \mathrm{MP}, 23 \mathrm{DMB}$, and $\mathrm{nH}$ reactants on $\mathrm{POM} / \mathrm{SiO}_{2}-\mathrm{Pt} / \mathrm{Al}_{2} \mathrm{O}_{3}$ mixtures with $\mathrm{Si}, \mathrm{Al}$, and Co central atoms were obtained by regression of rate data to the functional form of Eq. 5 at low (alkane/ $\mathrm{H}_{2}$ ) ratios $\left(75 \mathrm{kPa} \mathrm{H} \mathrm{H}_{2},<1.9 \mathrm{kPa}\right.$ alkane) .
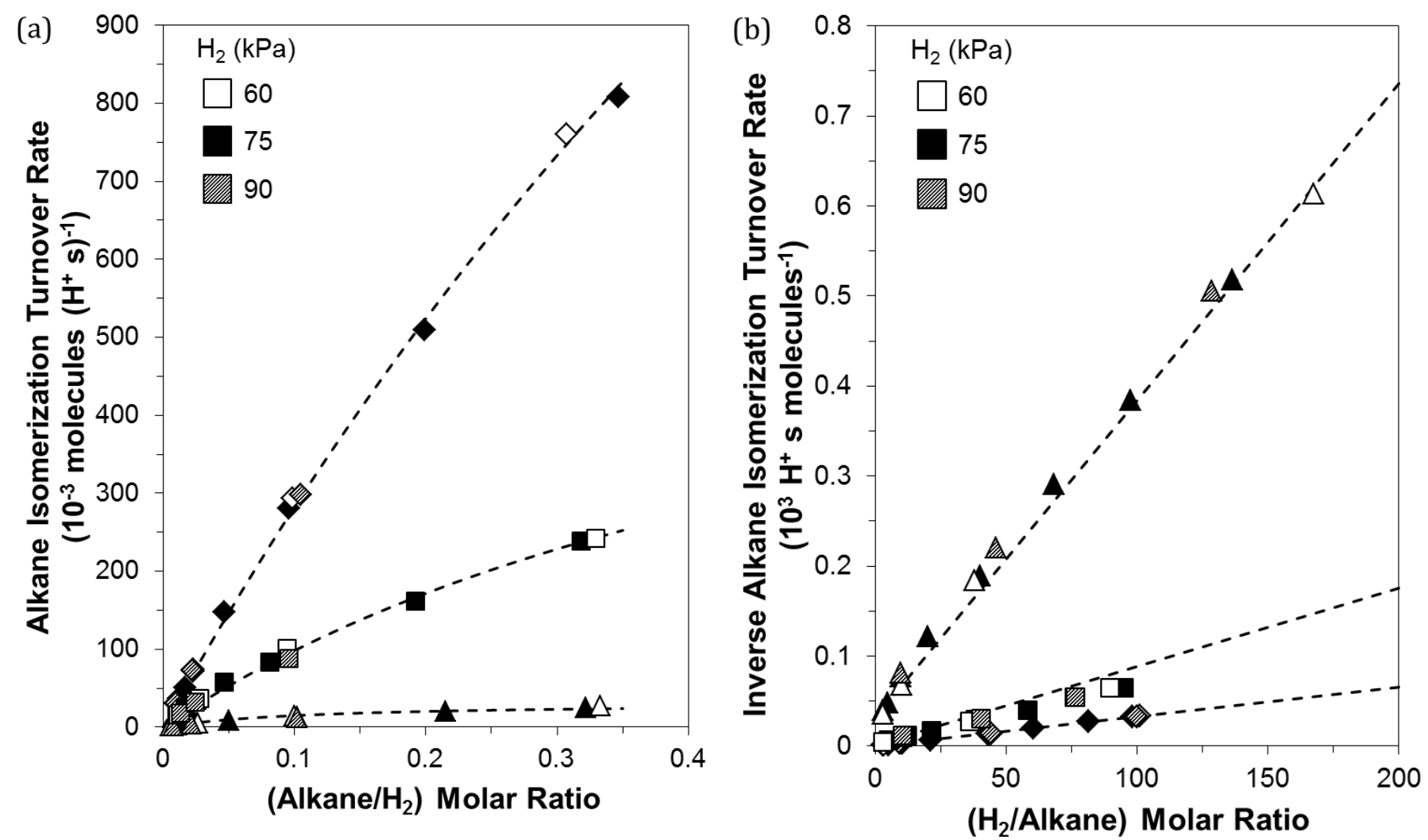

Figure 5. (a) Isomerization turnover rates as functions of the $\left([\mathrm{R}] / \mathrm{H}_{2}\right)$ ratio and (b) inverse isomerization turnover rates as functions of the $\left(\mathrm{H}_{2} /[\mathrm{R}]\right)$ ratio for $(\bullet)$ 3-methylpentane, (ם) 2,3-dimethylbutane, and $(\boldsymbol{\Delta})$ n-hexane reactants on $\mathrm{H}_{3} \mathrm{PW} / \mathrm{SiO}_{2}-\mathrm{Pt} / \mathrm{Al}_{2} \mathrm{O}_{3}\left(\mathrm{Pt}_{\mathrm{S}} / \mathrm{H}^{+}=11.7\right)$ (reaction conditions: $473 \mathrm{~K}, 0.5-25 \mathrm{kPa}$ alkane, $60-90 \mathrm{kPa}$ $\mathrm{H}_{2}$ ). Dashed lines represent the regression of the data to the functional form of Eq. 5. 
A rigorous analysis of the effects of acid strength on isomerization rate constants and selectivities requires that we dissect $\mathrm{k}_{\mathrm{isom}, \mathrm{R}} \mathrm{K}_{\text {prot }, \mathrm{R}}$ values into those for the formation of each individual isomer product $\left(\mathrm{k}_{\text {isom, } \mathrm{R} \rightarrow \mathrm{P}} \mathrm{K}_{\text {prot }, \mathrm{R}}\right)$. The data and discussion in Section 3.1.2 showed that measured alkane isomerization selectivities vary with reactant alkane pressure and do not reflect the selectivity for the formation of primary isomers (defined as those formed from reactant alkenes in one sojourn at an acid site); therefore, these selectivities cannot be used to calculate the individual formation rate for each isomer and to determine, in this manner, the $\mathrm{k}_{\mathrm{isom}, \mathrm{R} \rightarrow \mathrm{P}} \mathrm{K}_{\text {prot }, \mathrm{R}}$ values. This constraint precludes the determination of each $\mathrm{k}_{\mathrm{isom}, \mathrm{R} \rightarrow \mathrm{P}} \mathrm{K}_{\text {prot, } \mathrm{R}}$ value for most individual isomer products formed from each reactant (except approximately when one isomer predominates among products). As we show next, however, $\mathrm{k}_{\mathrm{isom}, 2 \rightarrow 3} \mathrm{~K}_{\text {prot, } 2}$ values, and consequently $2 \mathrm{MP}$ isomerization selectivities to $3 \mathrm{MP}$ and the ratio of those selectivities to those for isomerization products that vary backbone length, can be determined explicitly, without the use of measured product selectivities, from the measured lumped $\mathrm{k}_{\mathrm{isom}, \mathrm{R}} \mathrm{K}_{\text {prot, } \mathrm{R}}$ values for each isomer reactant.

The functional form of Eq. $3 b$ for each reactant allows one to expand $k_{\text {isom, } \mathrm{R}} K_{\text {prot, } R}$ values for each reactant " $\mathrm{R}$ " in terms of $\mathrm{k}_{\mathrm{isom}, \mathrm{R} \rightarrow \mathrm{P}} \mathrm{K}_{\text {prot, } \mathrm{R}}$ values for each product " $\mathrm{P}$ " formed from reactant " $\mathrm{R}$ " (noting that 22DMB formation is excluded from 23DMB conversion rates):

$$
\begin{gathered}
k_{\text {isom }, 2} K_{\text {prot }, 2}=k_{\text {isom }, 2 \rightarrow 3} K_{\text {prot }, 2}+k_{\text {isom }, 2 \rightarrow 23} K_{\text {prot }, 2}+k_{\text {isom }, 2 \rightarrow n H} K_{\text {prot }, 2} \\
k_{\text {isom }, 3} K_{\text {prot }, 3}=k_{\text {isom }, 3 \rightarrow 2} K_{\text {prot }, 3}+k_{\text {isom }, 3 \rightarrow 23} K_{\text {prot }, 3}+k_{\text {isom }, 3 \rightarrow n H} K_{\text {prot }, 3} \\
k_{\text {isom }, 23} K_{\text {prot }, 23}=k_{\text {isom }, 23 \rightarrow 2} K_{\text {prot }, 23}+k_{\text {isom }, 23 \rightarrow 3} K_{\text {prot }, 23}
\end{gathered}
$$




$$
k_{\text {isom }, n H} K_{p r o t, n H}=k_{\text {isom }, n H \rightarrow 2} K_{p r o t, n H}+k_{\text {isom }, n H \rightarrow 3} K_{p r o t, n H}
$$

These forward and reverse isomerization rate constants $\left(\mathrm{k}_{\mathrm{isom}, 2 \rightarrow 23} \mathrm{~K}_{\text {prot,2}}\right.$ and $\mathrm{k}_{\text {isom,23 } \rightarrow 2} \mathrm{~K}_{\text {prot,23 }}$ for example) are measured at reaction conditions where unoccupied $\mathrm{H}^{+}$ sites are the single most abundant surface species and alkoxide isomerization is the single kinetically-relevant step. In such cases, forward and reverse isomerization events are mediated by the same kinetically relevant transition state and must obey the principle of microscopic reversibility even when the isomerization reactions are far from equilibrium [31]. The ratio of the rate constants that describe such reactions is given by the equilibrium constant $\left(K_{e n e, R \leftrightarrow P}\right)$ for the overall reaction (i.e. formation of the equilibrated $\left[\mathrm{R}^{=}\right]$lump for product " $\mathrm{P}$ " from the equilibrated $\left[\mathrm{R}^{=}\right]$lump for reactant " $\mathrm{R}$ "), which may be calculated from tabulated gas phase thermodynamic data at the given reaction temperature $(473 \mathrm{~K})$ :

$$
\begin{aligned}
& K_{\text {ene }, 2 \leftrightarrow 3}=\frac{k_{\text {isom }, 2 \rightarrow 3} K_{p r o t, 2}}{k_{\text {isom }, 3 \rightarrow 2} K_{p r o t, 3}} \\
& K_{\text {ene }, 2 \leftrightarrow 23}=\frac{k_{\text {isom }, 2 \rightarrow 23} K_{\text {prot }, 2}}{k_{\text {isom }, 23 \rightarrow 2} K_{\text {prot }, 23}} \\
& K_{\text {ene }, 2 \leftrightarrow n H}=\frac{k_{\text {isom }, 2 \rightarrow n H} K_{p r o t, 2}}{k_{\text {isom }, n H \rightarrow 2} K_{p r o t, n H}} \\
& K_{\text {ene }, 23 \leftrightarrow 3}=\frac{k_{\text {isom }, 23 \rightarrow 3} K_{\text {prot }, 23}}{k_{\text {isom }, 3 \rightarrow 23} K_{\text {prot }, 3}} \\
& K_{\text {ene }, n H \leftrightarrow 3}=\frac{k_{\text {isom }, n H \rightarrow 3} K_{p r o t, n H}}{k_{\text {isom }, 3 \rightarrow n H} K_{p r o t, 3}}
\end{aligned}
$$

These relations can be used to simplify Eq. 6a-d to:

$$
\begin{gathered}
k_{\text {isom }, 2 \rightarrow 3} K_{\text {prot }, 2}=k_{\text {isom }, 2} K_{\text {prot }, 2}-k_{\text {isom }, 2 \rightarrow 23} K_{\text {prot }, 2}-k_{\text {isom }, 2 \rightarrow n H} K_{\text {prot }, 2} \\
k_{\text {isom }, 2 \rightarrow 3} K_{\text {prot }, 2}=k_{\text {isom }, 3} K_{\text {prot }, 3} K_{\text {ene }, 2 \leftrightarrow 3}-k_{\text {isom }, 3 \rightarrow 23} K_{\text {prot }, 3} K_{\text {ene }, 2 \leftrightarrow 3}-k_{\text {isom }, 3 \rightarrow n H} K_{\text {prot }, 3} K_{\text {ene }, 2 \leftrightarrow 3}
\end{gathered}
$$




$$
\begin{gathered}
0=-k_{\text {isom }, 23} K_{\text {prot }, 23} K_{\text {ene }, 2 \leftrightarrow 23}+k_{\text {isom }, 2 \rightarrow 23} K_{\text {prot }, 2}+k_{\text {isom }, 3 \rightarrow 23} K_{\text {prot }, 3} K_{\text {ene }, 2 \leftrightarrow 3} \\
0=-k_{\text {isom }, n H} K_{\text {prot }, n H} K_{\text {ene }, 2 \leftrightarrow n H}+k_{\text {isom }, 2 \rightarrow n H} K_{\text {prot }, 2}+k_{\text {isom }, 3 \rightarrow n H} K_{\text {prot }, 3} K_{\text {ene }, 2 \leftrightarrow 3}
\end{gathered}
$$

Adding Equations 8a to 8d, gives an explicit expression for $\mathrm{k}_{\mathrm{isom}, 2 \rightarrow 3} \mathrm{~K}_{\mathrm{prot}, 3}$ in terms of the measurable $\mathrm{k}_{\text {isom, } \mathrm{R}} \mathrm{K}_{\text {prot, } \mathrm{R}}$ and $\mathrm{K}_{\mathrm{ene}, 2 \leftrightarrow \mathrm{R}}$ values for each reactant:

$$
k_{\text {isom }, 2 \rightarrow 3} K_{\text {prot }, 2}=\frac{1}{2}\left(\begin{array}{rl}
k_{\text {isom }, 2} K_{\text {prot }, 2} & +k_{\text {isom }, 3} K_{\text {prot }, 3} K_{\text {ene }, 2 \leftrightarrow 3} \\
& -k_{\text {isom }, 23} K_{\text {prot }, 23} K_{\text {ene }, 2 \leftrightarrow 23}-k_{\text {isom }, n H} K_{p r o t, n H} K_{\text {ene }, 2 \leftrightarrow n H}
\end{array}\right)
$$

The selectivity to methyl-shift isomerization events relative to those events that vary backbone length $\left(\mathrm{s}_{\mathrm{MS}}\right)$ can then be calculated from $\mathrm{k}_{\mathrm{isom}, 2} \mathrm{~K}_{\mathrm{prot}, 2}$ and $\mathrm{k}_{\mathrm{isom}, 2 \rightarrow 3} \mathrm{~K}_{\mathrm{prot}, 2}$ values:

$$
S_{M S}=\frac{r_{\text {isom }, 2 \rightarrow 3}}{r_{\text {isom }, 2 \rightarrow 23}+r_{\text {isom }, 2 \rightarrow n H}}=\frac{k_{\text {isom }, 2 \rightarrow 3} K_{\text {prot }, 2}}{k_{\text {isom }, 2} K_{\text {prot }, 2}-k_{\text {isom }, 2 \rightarrow 3} K_{\text {prot }, 2}}
$$

Here, $r_{\text {isom }, 2 \rightarrow 3}, r_{i s o m, 2 \rightarrow 23}$, and $r_{i s o m, 2 \rightarrow n H}$ are, respectively, rates of methyl shift, branching, and chain lengthening isomerization events from $2 \mathrm{MP}^{=}$.

We conclude that first-order alkene isomerization rate constants measured on $\mathrm{POM} / \mathrm{SiO}_{2}-\mathrm{Pt} / \mathrm{Al}_{2} \mathrm{O}_{3}$ mixtures $\left(\mathrm{k}_{\mathrm{isom}, \mathrm{R}} \mathrm{K}_{\text {prot,R}}\right.$; Figure $\left.6 \mathrm{a}\right)$ reflect the reactivity of gaseous $\left[\mathrm{R}^{=}\right]$species in equilibrium with the reactant alkane at $\mathrm{H}^{+}$. From this mechanistic analysis, we can determine $\mathrm{k}_{\text {isom, } 2 \rightarrow 3} \mathrm{~K}_{\text {prot, } 2}$ values and selectivities for $3 \mathrm{MP}$ formation from $2 \mathrm{MP}$ explicitly and also the ratio of methyl shift events to those that lengthen or shorten the backbone $\left(\mathrm{s}_{\mathrm{MS}}\right)$ without the use of measured isomerization selectivities that reflect, in part, transport restrictions of product alkenes within acid domains instead of the rate constants for the formation of individual products from measured $\mathrm{k}_{\mathrm{isom}, \mathrm{R}} \mathrm{K}_{\mathrm{prot}, \mathrm{R}}$ values for each reactant. Values of $\mathrm{k}_{\text {isom, } 2 \rightarrow 3} \mathrm{~K}_{\text {prot,2}}$ reflect the free energy barrier for forming the transition state that mediates $2 \mathrm{MP}$ and $3 \mathrm{MP}$ interconversion from gaseous $2 \mathrm{MP}^{=}$; these 
values are used in Section 3.3 to assess the effects of acid strength on the stability of such transition states. Values of $\mathrm{s}_{\mathrm{MS}}$ indicate the tendency for $2 \mathrm{MP}$ reactants to methyl shift rather than branch or chain lengthen, thus providing a measure of isomerization product selectivities that is free of transport corruptions. In Section 3.4, $\mathrm{s}_{\mathrm{MS}}$ values determined for $\mathrm{POM} / \mathrm{SiO}_{2}-\mathrm{Pt} / \mathrm{Al}_{2} \mathrm{O}_{3}$ mixtures with $\mathrm{P}, \mathrm{Si}, \mathrm{Al}$, and $\mathrm{Co}$ central atoms are used to probe the effects of acid strength on isomerization selectivities.

\subsection{Mechanistic assessment of the effects of acid strength on isomerization rates}

Figure 6a shows $\mathrm{k}_{\mathrm{isom}, \mathrm{R}} \mathrm{K}_{\text {prot, } \mathrm{R}}$ values (in a logarithmic scale) for $2 \mathrm{MP}, 3 \mathrm{MP}$, 23DMB, and $\mathrm{nH}$ reactants on $\mathrm{POM} / \mathrm{SiO}_{2}-\mathrm{Pt} / \mathrm{Al}_{2} \mathrm{O}_{3}$ mixtures as a function of DPE values previously reported for $\mathrm{POM}$ clusters with $\mathrm{P}, \mathrm{Si}, \mathrm{Al}$, and $\mathrm{Co}$ central atoms [3]. The $\mathrm{k}_{\mathrm{isom}, \mathrm{R}} \mathrm{K}_{\text {prot,R}}$ value for each hexane isomer reactant decreases exponentially with increasing DPE. POM clusters with fewer protons (and higher-valent central atoms) have more stable conjugate anions and thus smaller DPE values, because the partial charge in protons leads to lower electron density for clusters with fewer protons and, consequently, higher electron affinity. The exponential effects of DPE on rate constants predominantly reflect concomitant effects on activation energies, instead of activation entropies $[3,8]$ because isomerization TS structures are similar on POM clusters with different central atom [8]. When DPE predominantly influences activation energies, the effects of DPE on $\mathrm{k}_{\mathrm{isom}, \mathrm{R}} \mathrm{K}_{\text {prot,R }}$ can be expressed in terms of derivatives as:

$$
\frac{d\left(\ln \left(k_{\text {isom }, R} K_{\text {prot }, R}\right)\right)}{d(D P E)}=\frac{1}{k_{\text {isom }, R} K_{\text {prot }, R}} \frac{d\left(k_{\text {isom }, R} K_{\text {prot }, R}\right)}{d(D P E)}=-\frac{1}{R T} \frac{d\left(E_{A, R}\right)}{d(D P E)}
$$


Here, $E_{A, R}$ is the measured activation barrier for reactant " $R$ ". The linear dependence of $\ln \left(\mathrm{k}_{\text {isom }, \mathrm{R}} \mathrm{K}_{\text {prot }, \mathrm{R}}\right)$ on DPE (Figure 6a) indicates that $\mathrm{d}\left(\mathrm{E}_{\mathrm{A}, \mathrm{R}}\right) / \mathrm{d}(\mathrm{DPE})$ values for all hexane isomer reactants are essentially independent of DPE on these POM clusters. The small values of the slopes of the dashed lines in Figure $6 \mathrm{a}\left(\mathrm{d}\left(\ln \left(\mathrm{k}_{\text {isom, } \mathrm{R}} \mathrm{K}_{\text {prot, } \mathrm{R}}\right)\right) / \mathrm{d}(\mathrm{DPE})=-0.03\right.$ mol $\mathrm{kJ}^{-1}$ for all reactants) and the functional form of Eq. 11 indicate that the measured activation energies vary in magnitude much less than the concomitant changes in DPE. Measured activation energies for all hexane isomer reactants were similarly sensitive to changes in DPE $\left(d\left(E_{A, R}\right) / d(D P E)=0.11\right)$, for which $k_{\text {isom }, \mathrm{R}} K_{\text {prot }, \mathrm{R}}$ rate constants vary by about a factor of 4 for each POM composition. Similar sensitivities of $\mathrm{k}_{\text {isom }, \mathrm{R}} \mathrm{K}_{\mathrm{prot}, \mathrm{R}}$ rate constants to changes in DPE for these different isomer reactants that form different sets of isomer products provides qualitative evidence that all isomerization events are similarly-dependent on DPE.

Isomerization leads to multiple products and $\mathrm{k}_{\text {isom, } \mathrm{R}} \mathrm{K}_{\mathrm{prot}, \mathrm{R}}$ is a lumped rate constant reflecting the total rate of isomerization of the gaseous equilibrated alkene lump for reactant " $\mathrm{R}$ " to each individual product "P" with rate constant $\mathrm{k}_{\mathrm{isom}, \mathrm{R} \rightarrow \mathrm{P}} \mathrm{K}_{\text {prot }, \mathrm{R}}$ (Eq. 6ad). Therefore, the effects of DPE on $\mathrm{k}_{\mathrm{isom}, \mathrm{R}} \mathrm{K}_{\mathrm{prot}, \mathrm{R}}$ are given by the summation of those on $\mathrm{k}_{\text {isom }, \mathrm{R} \rightarrow \mathrm{P}} \mathrm{K}_{\text {prot,R }}$ rate constants for each product "P" of reactant " $\mathrm{R}$ ":

$$
\frac{d\left(k_{\text {isom }, R} K_{\text {prot }, R}\right)}{d(D P E)}=\sum_{P} \frac{d\left(k_{\text {isom }, R \rightarrow P} K_{p r o t, R}\right)}{d(D P E)}
$$

Eq. 11 and equations analogous to Eq. 11 that describe the effects of DPE on each $\mathrm{k}_{\mathrm{isom}, \mathrm{R} \rightarrow \mathrm{P}} \mathrm{K}_{\text {prot, } \mathrm{R}}$ rate constant may be solved implicitly for each of the derivatives in Eq. 12. Filling these solutions into Eq. 12 shows that measured $d\left(E_{A, R}\right) / d(D P E)$ values are given by the rate-average (or selectivity-average) of those for each isomer product that a reactant forms: 


$$
\frac{d\left(E_{A, R}\right)}{d(D P E)}=\frac{\sum_{P} k_{\text {isom }, R \rightarrow P} K_{p r o t, R} \frac{d\left(E_{A, R \rightarrow P}\right)}{d(D P E)}}{k_{\text {isom }, R} K_{\text {prot }, R}}=\sum_{P} S_{R \rightarrow P} \frac{d\left(E_{A, R \rightarrow P}\right)}{d(D P E)}
$$

Here, $\mathrm{E}_{\mathrm{A}, \mathrm{R} \rightarrow \mathrm{P}}$ is the activation barrier to form the TS that gives the isomer product "P" from reactant " $R$ " and $S_{R \rightarrow P}$ is the selectivity to isomer product "P" from reactant " $R$ ". According to Eq. 13, $d\left(E_{\mathrm{A}, \mathrm{R}}\right) / \mathrm{d}(\mathrm{DPE})$ values that are similar for each reactant and essentially independent of DPE require the stability of all isomerization TS to be similarly sensitive to DPE (with $\left(\mathrm{E}_{\mathrm{A}, \mathrm{R} \rightarrow \mathrm{P}}\right) / \mathrm{d}(\mathrm{DPE})=0.11$ for all kinetically relevant isomerization steps). Such similar sensitivities would lead, in turn, to isomerization selectivities $\left(S_{R \rightarrow P}\right)$ that cannot depend on DPE (and acid strength) for acid POM clusters.

The relative stabilities of the ensembles of TS structures that mediate the isomerizations between $2 \mathrm{MP}, 3 \mathrm{MP}, 23 \mathrm{DMB}$, and $\mathrm{nH}$ reactants cannot be compared directly from their $E_{A, R}$ values because these activation energies are referenced to different reactants. The gaseous alkene reactant lumps $\left(\left[\mathrm{R}^{\overline{ }}\right]\right)$ have different gas-phase stabilities related to the equilibrium constant for the formation of the given equilibrated $\left[\mathrm{R}^{\overline{ }}\right]$ lump from a common reference equilibrated lump. In the context of transition state theory, $k_{\text {isom, } R \rightarrow P} K_{\text {prot }, R}$ values reflect free energy barriers $\left(\Delta G_{R \rightarrow P}^{\ddagger}\right)$ given by the difference between the free energies for the TS that mediates the conversion of " $\mathrm{R}$ " to "P" (or "P" to "R", $\left.G_{P \leftrightarrow R}^{\ddagger}\right)$ and for the gaseous alkene reactant lump $\left(G_{\text {ene, },}\right)$ :

$$
\Delta G_{R \rightarrow P}^{\ddagger}=G_{R \leftrightarrow P}^{\ddagger}-G_{e n e, R}=-R T \ln \left(\frac{h}{k_{B} T} k_{i s o m, R \rightarrow P} K_{p r o t, R}\right)
$$

Here, $\mathrm{k}_{\mathrm{B}}$ and $\mathrm{h}$ are the Boltzmann and Planck constants, respectively. Free energy barriers calculated in this manner using $\mathrm{k}_{\mathrm{isom}, \mathrm{R}} \mathrm{K}_{\text {prot, } \mathrm{R}}$ rate constants $\left(\Delta \mathrm{G}_{\mathrm{R}}^{\dagger}\right)$ can be related to those 
for each product formed using the functional form of Eq. $3 \mathrm{~b}$ for the given reactant "R" and Eq. 14 (shown in Scheme 3 for 2MP, 3MP and 23DMB reactants):

$$
\Delta G_{R}^{\ddagger}=-R T \ln \left(\sum_{P} \exp \left(\frac{-\left(G_{R \leftrightarrow P}^{\ddagger}-G_{\text {ene, } R}\right)}{R T}\right)\right)=-R T \ln \left(\frac{h}{k_{B} T} k_{\text {isom }, R} K_{p r o t, R}\right)
$$

Here, $\Delta \mathrm{G}_{\mathrm{R}}^{\ddagger}$ accounts for the additive contributions of all TS to measured $\mathrm{k}_{\mathrm{isom}, \mathrm{R}} \mathrm{K}_{\text {prot, } \mathrm{R}}$ values. The free energy difference between the gaseous alkene lump $\left(\left[R^{=}\right]\right)$species and the gaseous $2 \mathrm{MP}^{=}\left(\Delta \mathrm{G}_{\mathrm{ene}, 2 \leftrightarrow \mathrm{R}}\right)$ can be added to both sides of Eq. 15 to make all TS energies relative to the same reference state (gaseous $2 \mathrm{MP}^{\overline{ }}$ ):

$$
\Delta G_{R}^{\ddagger}{ }_{R}=\Delta G_{R}^{\ddagger}+\Delta G_{e n e, 2 \leftrightarrow R}=-R T \ln \left(\sum_{P} \exp \left(\frac{-\left(G_{R \leftrightarrow P}^{\ddagger}-G_{e n e, 2}\right)}{R T}\right)\right)
$$

In this case, $\Delta \mathrm{G}^{\ddagger}{ }_{\mathrm{R}}$ is the free energy barrier for the ensemble of TS accessible to reactant "R" referenced to gaseous $2 \mathrm{MP}^{=}$(shown in Scheme 3 for $2 \mathrm{MP}^{=}, 3 \mathrm{MP}^{=}$and $23 \mathrm{DMB}^{=}$ reactants) and $\mathrm{G}_{\mathrm{ene}, 2}$ is the free energy for the gaseous $2 \mathrm{MP}^{=}$. We can then compare $\Delta \mathrm{G}^{\ddagger}{ }_{\mathrm{R}}$ values for each reactant to those for $2 \mathrm{MP}$ by taking the ratio of the isomerization rate constant for each reactant isomer $\left(\mathrm{k}_{\mathrm{isom}, \mathrm{R}} \mathrm{K}_{\mathrm{prot}, \mathrm{R}}\right)$ (normalized by the equilibrium constant for forming the gaseous reactant alkene lump $\left[\mathrm{R}^{=}\right]$from gaseous $\left.2 \mathrm{MP}^{=}\left(\mathrm{K}_{\text {ene, } 2 \leftrightarrow R}\right)\right)$ to the isomerization rate constant for $2 \mathrm{MP}\left(\mathrm{k}_{\mathrm{isom}, 2} \mathrm{~K}_{\mathrm{prot}, 2}\right)$ :

$$
\alpha_{R, 2}=\frac{k_{\text {isom }, R} K_{\text {prot }, R} K_{\text {ene }, 2 \leftrightarrow R}}{k_{\text {isom }, 2} K_{\text {prot }, 2}}=\exp \left(\frac{-\left(\Delta G^{\ddagger}{ }_{R}-\Delta G_{2}^{\ddagger}\right)}{R T}\right)
$$

The value of $\alpha_{R, 2}$ reflects the free energy difference between that for the isomerization TS structures accessible to reactant " $\mathrm{R}$ " and that for the TS structures accessible to $2 \mathrm{MP}=$, thus providing a rigorous assessment of the relative stability of the two ensembles of transition states $\left(\Delta \mathrm{G}^{\ddagger}{ }_{\mathrm{R}}-\Delta \mathrm{G}_{2}^{\ddagger}\right)$. The $\alpha_{\mathrm{R}, 2}$ values determined for 3MP, 23DMB and $\mathrm{nH}$ 
reactants are essentially independent of DPE on W-POM acids with different central atoms (Figure $6 \mathrm{~b}$ ) because $\mathrm{k}_{\mathrm{isom}, \mathrm{R}} \mathrm{K}_{\text {prot, } \mathrm{R}}$ values for each alkane reactant depend similarly on acid strength. Values of $\alpha_{R, 2}$ are near unity for $3 \mathrm{MP}$ because $2 \mathrm{MP}$ and $3 \mathrm{MP}$ predominantly form each other during their respective isomerization reactions via the same transition state. The $\alpha_{\mathrm{R}, 2}$ values for $23 \mathrm{DMB}$ and $\mathrm{nH}$ reactants are much smaller than unity $(0.20 \pm 0.02$ and $0.068 \pm 0.008$ for $23 \mathrm{DMB}$ and $\mathrm{nH}$, respectively) because the transition states for chain lengthening and shortening (the predominant isomerization events for $23 \mathrm{DMB}$ and $\mathrm{nH}$ reactants, respectively) are less stable than those that mediate methyl shifts (the predominant isomerization event for 2MP reactants). Eq. 17 indicates gives free energy barrier differences that indicate free energy barriers are $6.3 \pm 0.4 \mathrm{~kJ}$ $\mathrm{mol}^{-1}$ and $10.5 \pm 0.4 \mathrm{~kJ} \mathrm{~mol}^{-1}$ lower for $2 \mathrm{MP}$ isomerization than for 23DMB and $\mathrm{nH}$ isomerization, respectively.

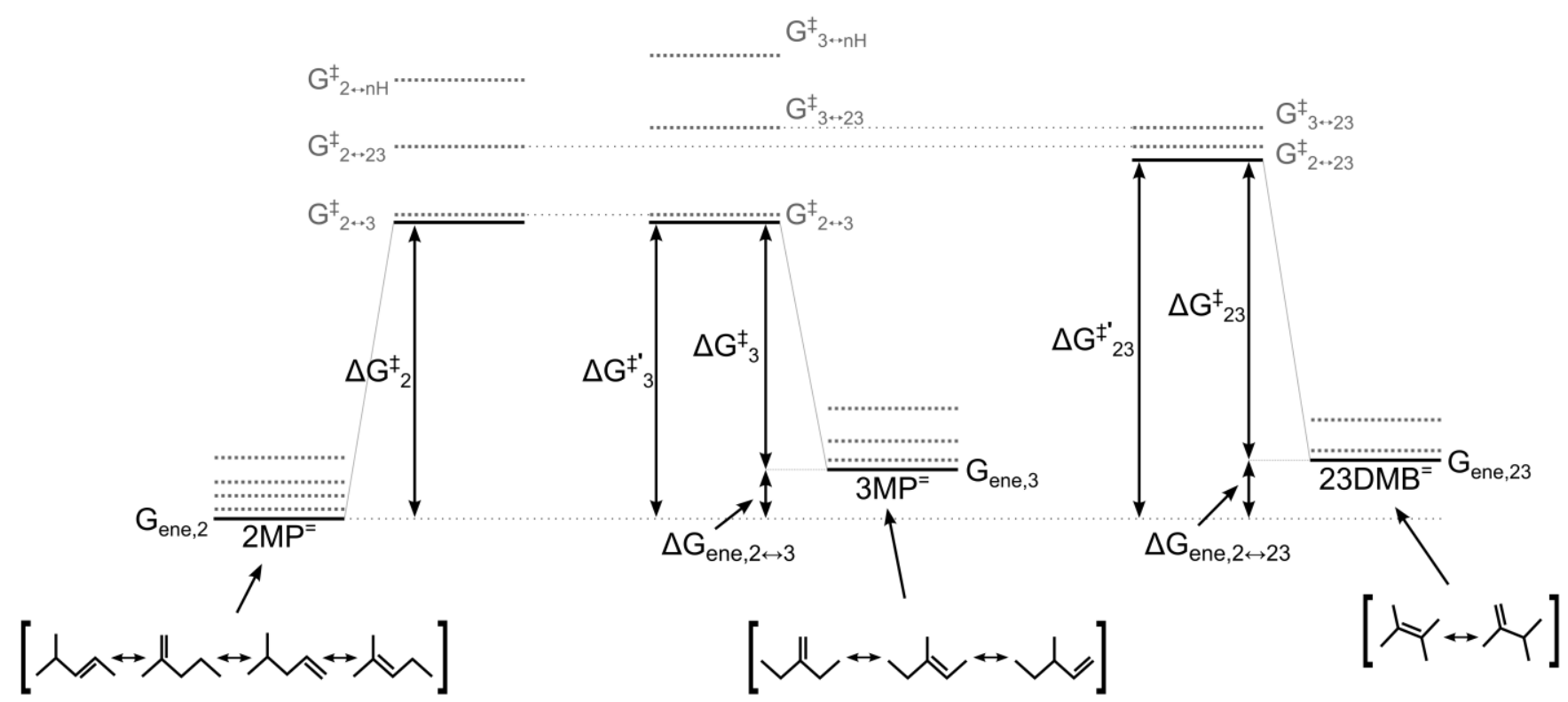

Scheme 3. Reaction coordinate diagram depicting the free energies of $2 \mathrm{MP}=\left(\mathrm{G}_{\mathrm{ene}, 2}\right), 3 \mathrm{MP}=\left(\mathrm{G}_{\text {ene, } 3}\right)$, and $23 \mathrm{DMB}=\left(\mathrm{G}_{\mathrm{ene}, 23}\right)$ regioisomer isomer groups and the free energies of the isomerization transition states accessible to each of these groups $\left(2 \mathrm{MP}^{=}: \mathrm{G}_{2 \leftrightarrow 3}^{\ddagger}, \mathrm{G}_{2 \leftrightarrow 23}^{\ddagger}\right.$, and $\mathrm{G}_{2 \leftrightarrow \mathrm{nH}}^{\ddagger} ; 3 \mathrm{MP}^{=}: \mathrm{G}_{2 \leftrightarrow 3}^{\ddagger}, \mathrm{G}_{3 \leftrightarrow 23}^{\ddagger}$ and $\mathrm{G}_{3 \leftrightarrow \mathrm{nH}}^{\ddagger}$; $23 \mathrm{DMB}^{=}: \mathrm{G}_{2 \leftrightarrow 23}^{\ddagger}$ and $\left.\mathrm{G}_{3 \leftrightarrow 23}^{\ddagger}\right)$. Free energy barriers for $\mathrm{k}_{\mathrm{isom}, 2} \mathrm{~K}_{\text {prot, } 2}\left(\Delta \mathrm{G}_{2}^{\ddagger}\right), \mathrm{k}_{\text {isom, } 3} \mathrm{~K}_{\text {prot }, 3}\left(\Delta \mathrm{G}_{3}^{\star}\right)$, 
$\mathrm{k}_{\text {isom }, 23} \mathrm{~K}_{\text {prot }, 23}\left(\Delta \mathrm{G}^{\ddagger}{ }_{23}\right), \mathrm{k}_{\text {isom, } 3} \mathrm{~K}_{\text {prot }, 3} \mathrm{~K}_{\text {ene, } 2 \leftrightarrow 3}\left(\Delta \mathrm{G}^{\ddagger}{ }_{3}\right)$, and $\mathrm{k}_{\text {isom, } 23} \mathrm{~K}_{\text {prot,23 }} \mathrm{K}_{\text {ene, } 2 \leftrightarrow 23}\left(\Delta \mathrm{G}^{\ddagger}{ }_{23}\right)$ and free energy differences for $\mathrm{K}_{\mathrm{ene}, 2 \leftrightarrow 3}\left(\Delta \mathrm{G}_{\mathrm{ene}, 2 \leftrightarrow 3}\right)$ and $\mathrm{K}_{\mathrm{ene}, 2 \leftrightarrow 23}\left(\Delta \mathrm{G}_{\mathrm{ene}, 2 \leftrightarrow 23}\right)$ are also shown.
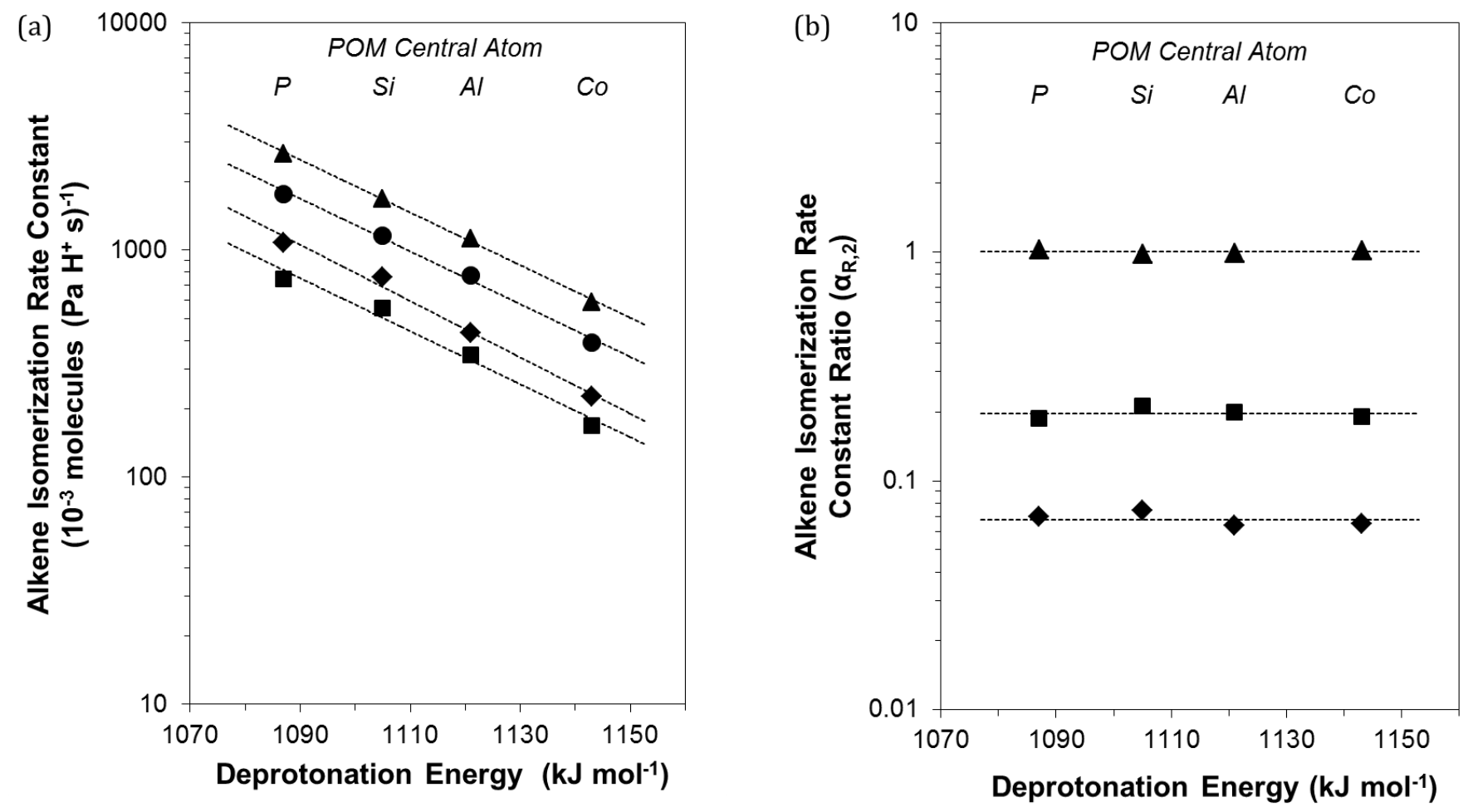

Figure 6. (a) Alkene isomerization rate constants $\left(\mathrm{k}_{\text {isom, } \mathrm{R}} \mathrm{K}_{\text {prot }, \mathrm{R}}\right)$ for $(\bullet)$ 2-methylpentane, ( $\left.\mathbf{\Delta}\right)$ 3-methylpentane,

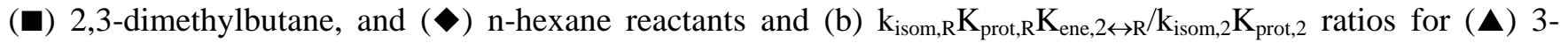
methylpentane, $(\boldsymbol{\square})$ 2,3-dimethylbutane, and $(\diamond)$ n-hexane reactants as functions of deprotonation energy for $\mathrm{H}_{8-}$ ${ }_{\mathrm{n}} \mathrm{X}^{\mathrm{n}+} \mathrm{W}_{12} \mathrm{O}_{40}(\mathrm{X}=\mathrm{P}, \mathrm{Si}, \mathrm{Al}, \mathrm{Co})(473 \mathrm{~K})$. The dashed lines in (a) are exponential fits of the data to deprotonation energies for Keggin clusters and in (b) are the averages of the data for each ratio.

\subsection{Mechanistic assessment of the effects of acid strength on isomerization}

\section{transition state energies}

The following discussion assesses calculated $\mathrm{k}_{\text {isom, }{ }_{\rightarrow} 3} \mathrm{~K}_{\text {prot,2 }}$ values (Eq. 9) mechanistically, then further analyzes their values in more detail using thermochemical cycles. In doing so, we seek to probe how specific catalyst properties determine the stability of individual isomerization transition states and what causes the significant attenuation of DPE effects on activation barriers for such transition states. Figure 7 shows 
values of $\mathrm{k}_{\mathrm{isom}, 2{ }_{3} 3} \mathrm{~K}_{\text {prot,2}}$, calculated from $\mathrm{k}_{\mathrm{isom}} \mathrm{K}_{\text {prot, } \mathrm{R}}$ values using the functional form of Eq. 9, for 2MP, 3MP, 23DMB, and $\mathrm{nH}$ reactant on POM clusters with $\mathrm{P}, \mathrm{Si}, \mathrm{Al}$, and Co central atoms as a function of their DPE. The slope of the dashed line for the $\mathrm{k}_{\text {isom, } 2_{\rightarrow} 3} \mathrm{~K}_{\text {prot }, 2}$ data in Figure $7\left(\mathrm{~d}\left(\ln \left(\mathrm{k}_{\text {isom, },{ }_{3} 3} \mathrm{~K}_{\text {prot }, 2}\right)\right) / \mathrm{d}(\mathrm{DPE})=-0.03 \mathrm{~mol} \mathrm{~kJ}{ }^{-1}\right)$ is much smaller than unity, indicating, according to an equation analogous to Eq. 11 describing the effects of DPE on $\mathrm{k}_{\text {isom, } 2 \rightarrow 3} \mathrm{~K}_{\text {prot,2, }}$, that activation barriers for methyl shift isomerization transition states differ in energy among catalysts much less than their concomitant changes in $\operatorname{DPE}\left(\mathrm{d}\left(\mathrm{E}_{\mathrm{A}, 2 \rightarrow 3}\right) / \mathrm{d}(\mathrm{DPE})=0.11<1\right)$. Scheme 4 shows the reaction coordinate for $2 \mathrm{MP}^{=}$(shown as 2-methylpent-2-ene as the example) conversion to $3 \mathrm{MP}^{=}$and the energies that determine the activation barrier reflected in its lumped kinetic parameter $\left(\mathrm{k}_{\mathrm{isom}, 2}{ }_{3} \mathrm{~K}_{\text {prot }, 2}\right)$. Activation energies for $\mathrm{k}_{\mathrm{isom}, 2}{ }_{3} \mathrm{~K}_{\text {prot,2}}$ include the energies to protonate the lumped gaseous $2 \mathrm{MP}^{=}$species by reaction with protons at POM Brønsted acid sites ( $E_{\text {prot }}$ in Scheme 4) and to rearrange 2MP* species to form the transition state that mediates methyl shifts for the equilibrated mixtures of adsorbed alkoxides ( $\mathrm{E}_{\mathrm{isom}, 3 \mathrm{MP}}$ in Scheme 4). Thermochemical cycles are used next to dissect these methyl shift activation energies into those for a sequence of hypothetical steps, for which experiments or calculations can provide accurate energies, using a formalism previously applied to alkanol dehydration [3,7] and n-hexane isomerization [8] reactions on solid acids. 


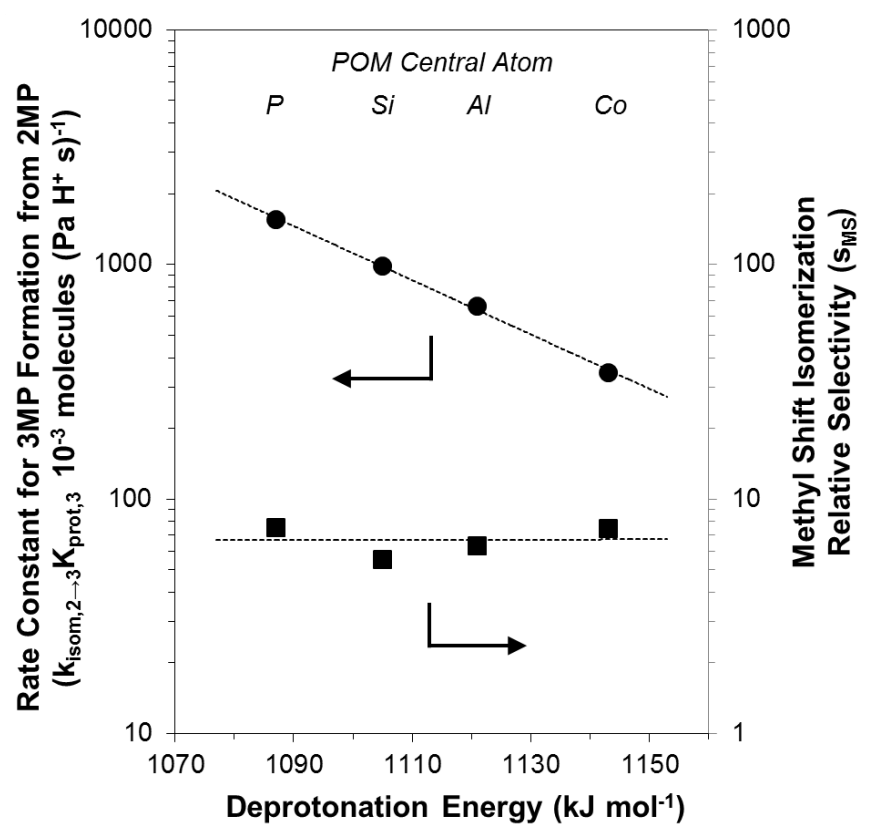

Figure 7. Rate constants for 2-methylpentene isomerization to 3methylpentene $\left(\mathrm{k}_{\text {isom }, 2 \rightarrow 3} \mathrm{~K}_{\text {prot }, 2}, \quad\right.$ O) and selectivities for methyl shift isomerization events relative to isomerization events that vary backbone length $\left(\mathrm{s}_{\mathrm{MS}}, \mathbf{\square}\right)$ at $473 \mathrm{~K}$ as a function of deprotonation energy for $\mathrm{H}_{8-\mathrm{n}} \mathrm{X}^{\mathrm{n}+} \mathrm{W}_{12} \mathrm{O}_{40}(\mathrm{X}=\mathrm{P}, \mathrm{Si}, \mathrm{Al}, \mathrm{Co})$. The dashed lines are an exponential fit of $\mathrm{k}_{2 \rightarrow 3}$ values to deprotonation energies and the average of $\mathrm{s}_{\mathrm{MS}}$ values for Keggin clusters.

A thermochemical cycle that converts gaseous $2 \mathrm{MP}^{=}$species into the methyl shift transition state (Scheme 4) involves deprotonation (DPE) of the POM clusters by overcoming interactions of $\mathrm{H}^{+}$with conjugate anion, formation of gaseous cycloalkyl carbenium ions resembling the TS cation (structure resembles Scheme 4 (A) for $2 \mathrm{MP}$ $3 \mathrm{MP}$ interconversion) by reactions of gaseous $\mathrm{H}^{+}$and $2 \mathrm{MP}^{-}\left(\mathrm{E}_{\text {gas, } 2 \rightarrow 3}\right)$, and the interaction energy between the gaseous TS cations and the conjugate anion of the POM solid acid at the TS $\left(\mathrm{E}_{\mathrm{int}, 2 \rightarrow 3}\right)$ :

$$
E_{A, 2 \rightarrow 3}=D P E+E_{g a s, 2 \rightarrow 3}+E_{i n t, 2 \rightarrow 3}
$$

Here, DPE and $\mathrm{E}_{\mathrm{int}, 2 \rightarrow 3}$ reflect ion-pair interactions of $\mathrm{H}^{+}$and TS cation, respectively, with the same POM anion. Such interactions typically involve an ionic component 
reflecting classical electrostatic interactions between ions, when they approach each other, and a covalent component reflecting structural and electronic relaxation induced by ions in close proximity with each other [9]. The $E_{g a s, 2 \rightarrow 3}$ value is the energy required to form the gaseous analog of the relevant cycloalkyl carbenium ion transition state $\left(\left[\mathrm{C}_{6} \mathrm{H}_{13}{ }^{\ddagger}\right]^{+}{ }_{(\mathrm{g})}\right)$ from gaseous $2 \mathrm{MP}^{=}$and a free gaseous $\mathrm{H}^{+}$:

$$
2 M P_{(g)}^{=}+H_{(g)}^{+} \rightarrow\left[C_{6} H_{13}^{\ddagger}\right]_{(g)}^{+}
$$

The sensitivity of each energy term in the thermochemical cycle (Eq. 18) to DPE ultimately accounts for the observed effects of DPE on $\mathrm{k}_{\mathrm{isom}, 2{ }_{3}} \mathrm{~K}_{\text {prot,2 }}$ values (Figure 7):

$$
\frac{d\left(E_{A, 2 \rightarrow 3}\right)}{d(D P E)}=1+\frac{d\left(E_{i n t, 2 \rightarrow 3}\right)}{d(D P E)}
$$

The term for $\mathrm{d}\left(\mathrm{E}_{\mathrm{gas}, 2 \rightarrow 3}\right) / \mathrm{d}(\mathrm{DPE})$ is absent in Eq. 20 (even though it appears in Eq. 18), because $E_{\text {gas }, 2 \rightarrow 3}$ is a property of the gaseous species (Eq. 19) and thus unaffected by the identity or DPE of the acid catalyst. Activation energies of methyl shift isomerizations $\left(\mathrm{E}_{\mathrm{A}, 2 \rightarrow 3}\right)$ increase less than the commensurate changes in DPE because interactions between the conjugate anion and cationic moieties at TS recover a large fraction of the additional energy needed to deprotonate weaker acids, as also shown previously for acid catalyzed reactions that are mediated by ion-pair transition states $[3,7]$. Thus, weaker acids have larger DPE values and more negative values of $E_{\text {int, } 2 \rightarrow 3}$ that offset each other in activation energies. 


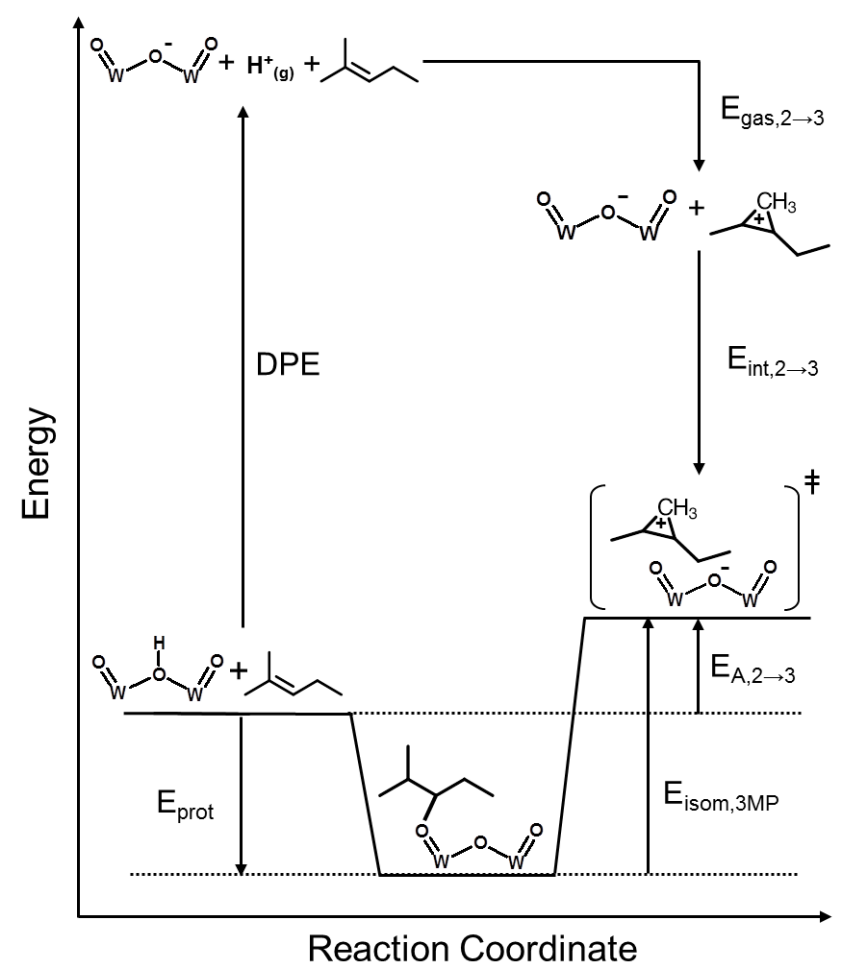

Scheme 4. Thermochemical cycle accounting for activation energies of Brønsted acid-catalyzed isomerization reactions (shown for 3MP products). Activation energies of $\mathrm{k}_{\mathrm{isom}, 2 \rightarrow 3} \mathrm{~K}_{\mathrm{prot}, 2}\left(\mathrm{E}_{\mathrm{A}, 2 \rightarrow 3}\right)$ are the sum of the intrinsic isomerization activation energies $\left(\mathrm{E}_{\text {isom,3MP }}\right)$ and 2methylpentene protonation energies at the acid site $\left(\mathrm{E}_{\mathrm{prot}}\right) . \mathrm{E}_{\mathrm{A}, 2 \rightarrow 3}$ values depend on catalyst deprotonation energies (DPE), gas-phase protonation of the alkene to form the gaseous analog of the transition state $\left(\mathrm{E}_{\mathrm{gas}, 2 \rightarrow 3}\right)$, and transition state interaction energies $\left(\mathrm{E}_{\mathrm{int}, 2 \rightarrow 3}\right)$.

Mechanistic assessments of rate constants for the formation of other individual isomerization products from $2 \mathrm{MP}^{=}$or any of the other alkenes $\left(\mathrm{k}_{\text {isom, } \mathrm{R}, \mathrm{P}} \mathrm{K}_{\text {prot, } \mathrm{R}}\right)$ lead to similar thermochemical cycles and consequently to equations similar to that for $\mathrm{k}_{\text {isom, }{ }_{\rightarrow}{ }_{3}} \mathrm{~K}_{\text {prot,2}}$ (Eq. 20). The replacement of the $\mathrm{d}\left(\mathrm{E}_{\mathrm{A}, \mathrm{R} \rightarrow \mathrm{P}}\right) / \mathrm{d}(\mathrm{DPE})$ term in Eq. 13 with equations analogous to Eq. 20 for each hexane isomer shows that the attenuation of the effects of DPE on the activation barriers $\left(\mathrm{d}\left(\mathrm{E}_{\mathrm{A}, \mathrm{R}}\right) / \mathrm{d}(\mathrm{DPE})<1\right)$ for $\mathrm{k}_{\mathrm{isom}, \mathrm{R}} \mathrm{K}_{\mathrm{prot}, \mathrm{R}}$ rate 
constants $\left(E_{A, R}\right)$ reflect the selectivity-average of those for $k_{i s o m, R_{\rightarrow} P} K_{\text {prot, } R}$ for each reactant

$$
\frac{d\left(E_{A, R}\right)}{d(D P E)}=1+\sum_{P} \frac{k_{i s o m, R \rightarrow P} K_{p r o t, R}}{k_{\text {isom }, R} K_{p r o t, R}} \frac{d\left(E_{\text {int }, R \rightarrow P}\right)}{d(D P E)}=1+\sum_{P} S_{R \rightarrow P} \frac{d\left(E_{\text {int }, R \rightarrow P}\right)}{d(D P E)}
$$

Here, $E_{\text {int, } R \rightarrow P}$ values reflect the ionic and covalent interactions between the conjugate anion and the TS that is kinetically relevant for the conversion of each reactant " $\mathrm{R}$ " to each product " $P$ " and $S_{R \rightarrow P}$ is the selectivity to isomer product "P" from reactant " $R$ ". The linear dependence of $\ln \left(\mathrm{k}_{\mathrm{isom}, \mathrm{R}} \mathrm{K}_{\text {prot } \mathrm{R}}\right)$ on DPE (Figure 6a) indicates, according to the functional form of Eq. 11, that $\mathrm{d}\left(\mathrm{E}_{\mathrm{A}, \mathrm{R}}\right) / \mathrm{d}(\mathrm{DPE})$ values and, in turn, the right side of Eq. 21 are similar for all hexane isomer reactants and essentially independent of DPE on these POM clusters. These results suggests that $E_{\text {int, } R \rightarrow P}$ values for all the transitions states that interconvert all hexene isomers depend similarly on DPE (with $d\left(E_{i n t, R \rightarrow P}\right) / d(D P E)=-0.89$ for every one of the isomerization reactions); consequently, isomerization selectivities $\left(\mathrm{S}_{\mathrm{R} \rightarrow \mathrm{P}}\right)$ are independent DPE on these POM clusters. The factors responsible for such similar DPE effects on selectivities are discussed in the next section.

\subsection{Mechanistic assessment of the effects of acid strength on isomerization selectivities}

In this section, calculated $\mathrm{s}_{\mathrm{MS}}$ values for $2 \mathrm{MP}$ reactants (Eq. 10) are assessed mechanistically, and then analyzed in more detail using the thermochemical cycles of Section 3.3. Figure 7 shows measured $\mathrm{s}_{\mathrm{MS}}$ values for $2 \mathrm{MP}$ reactants on $\mathrm{POM} / \mathrm{SiO}_{2^{-}}$ $\mathrm{Pt} / \mathrm{Al}_{2} \mathrm{O}_{3}$ mixtures (P, Si, Al, Co central atoms) as a function of their DPE values. Values of $\mathrm{S}_{\mathrm{MS}}$ were greater than unity and essentially independent of DPE on these POM mixtures, having a mean value of $6.7 \pm 1.5$ (95\% confidence interval). Such $\mathrm{s}_{\mathrm{MS}}$ values 
greater than unity suggest that the cycloalkyl carbenium ion transition states that form 23DMB and $\mathrm{nH}$ from 2MP reactants (Scheme $4(\mathrm{~B})$ and (C), respectively) are less stable than those that form 3MP from 2MP reactants (Scheme $4(\mathrm{~A})$ ), consistent with lower DFT-derived activation barriers for reactions on an aluminosilicate site that form 3methyl-2-pentene from 2-methylpent-2-ene $(71 \mathrm{~kJ} / \mathrm{mol})$ [27] than those forming 2,3dimethyl-2-butene from 2-methylpent-2-ene $(117 \mathrm{~kJ} / \mathrm{mol})$ [27].

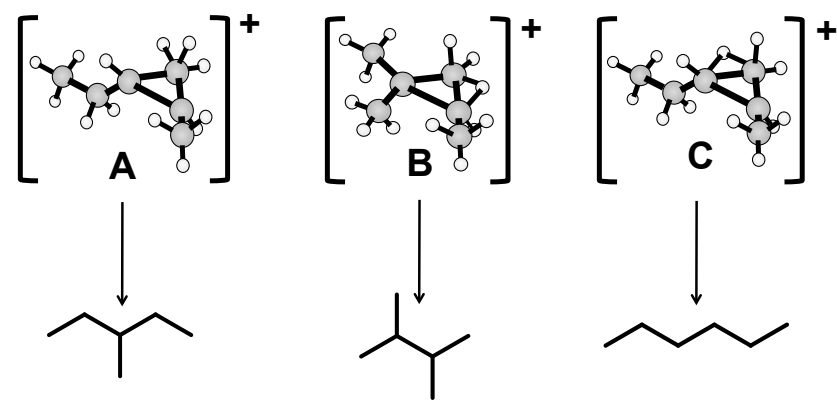

Scheme 5. Proposed cyclopropyl carbenium ions at isomerization transition states forming (A) 3-methylpentane, (B) 2,3-dimethylbutane, and $(\mathrm{C}) \mathrm{n}$-hexane [27]. 3-Methylpentane transition states involve cleavage and formation of $\mathrm{C}-\mathrm{C}$ bonds to shift the methyl group along the hydrocarbon backbone. 2,3-Dimethylbutane and n-hexane transition states involve concerted cleavage and formation of $\mathrm{C}-\mathrm{C}$ and $\mathrm{C}-\mathrm{H}$ bonds to rearrange the hydrocarbon backbone.

The significant role of $\mathrm{E}_{\mathrm{gas}, \mathrm{R} \rightarrow \mathrm{P}}$ in determining the magnitude of activation energies (Eq. 18), but not their dependence on DPE (Eq. 20), indicates that reactions that are more demanding (i.e., have larger activation energies) do not necessarily sense acid strength more strongly (i.e., exhibit a larger slope with DPE). The effects of acid strength on isomerization selectivities reflect only the relative ability of these cationic transition states to recover differences in DPE among acids through concomitant changes in their interaction energies with the conjugate anions of these acids. "Proton-like" transition states with localized positive charges that can closely approach the anion interact more 
strongly with the anion, which leads to weaker DPE effects on their activation energies than that of larger transition states with more diffuse positive charges.

When pre-exponential factors are essentially independent of DPE (Section 3.2), the effects of DPE on $\mathrm{s}_{\mathrm{MS}}$ values is given by:

$$
\frac{d\left(\ln \left(s_{M S}\right)\right)}{d(D P E)}=-\frac{1}{R T}\left(\frac{d\left(E_{i n t, 2 \rightarrow 3}\right)}{d(D P E)}-\frac{d\left(E_{i n t, 2 \rightarrow 23+n H}\right)}{d(D P E)}\right)
$$

because DPE effects on isomerization activation barriers depend only on the concomitant effects on transition state interaction energies (Eq. 17). Here, $\mathrm{E}_{\mathrm{int}, 2 \rightarrow 23+\mathrm{nH}}$ is the rateaveraged interaction energy for the transition states that mediate $\mathrm{nH}$ and 23DMB formation from 2MP defined by:

$$
E_{\text {int }, 2 \rightarrow 23+n H}=\frac{k_{\text {isom }, 2 \rightarrow 23}}{k_{\text {isom }, 2 \rightarrow 23}+k_{\text {isom }, 2 \rightarrow n H}} E_{\text {int }, 2 \rightarrow 23}+\frac{k_{\text {isom }, 2 \rightarrow n H}}{k_{\text {isom }, 2 \rightarrow 23}+k_{\text {isom }, 2 \rightarrow n H}} E_{\text {int }, 2 \rightarrow n H}
$$

The $\mathrm{s}_{\mathrm{MS}}$ values are essentially independent of DPE (Figure 7), indicating that interaction energies are similarly sensitive to changes in DPE for the transition states that mediate methyl shift, branching, and chain lengthening isomerizations events $\left(\mathrm{d}\left(\mathrm{E}_{\mathrm{int}, 2 \rightarrow 3}\right) / \mathrm{d}(\mathrm{DPE})=\right.$ $\mathrm{d}\left(\mathrm{E}_{\text {int, } 2 \rightarrow 23+\mathrm{nH}}\right) / \mathrm{d}(\mathrm{DPE})=-0.89$ in Eq. 22). The similar amount and location of cationic charge at these TS causes them to recover a similar fraction of the DPE changes among these clusters. In such cases, the specific kinetic hurdles for a given isomerization event (reflected in the magnitude of $E_{g a s, R \rightarrow P}$ for that reaction in Eq. 18) does not influence how this activation barrier varies with acid strength.

This mechanistic analysis shows that $\mathrm{s}_{\mathrm{MS}}$ values rigorously reflect the differences in free energy barriers between TS that shift the methyl group and those that vary backbone length of $2 \mathrm{MP}$ reactants, and, as a result, provide a probe of primary product selectivities (defined as those formed from reactant alkenes in one surface sojourn) free 
of transport artifacts. The value of $\mathrm{s}_{\mathrm{MS}}$, or the tendency of alkenes with $2 \mathrm{MP}$ backbones to form alkenes with $3 \mathrm{MP}, \mathrm{nH}$, or 23DMB backbones, is unaffected by the DPE, and thus the acid strength, of POM clusters because of the similar amount and localization of cationic charge at all isomerization TS. In such cases, acid strength alone cannot be used to improve the selective isomerization to any one of these hexane isomers from a given reactant, nor can it be used for any other conversion where TS cations in competing pathways have similar charge amount and localization.

\section{Conclusions}

The effects of acid strength on reactivity and selectivity are demonstrated using 2methylpentane (2MP), 3-methylpentane (3MP), 2,3-dimethylbutane (23DMB), and nhexane $(\mathrm{nH})$ isomerization routes on well-defined solid Brønsted acids in mixtures with $\mathrm{Pt} / \mathrm{Al}_{2} \mathrm{O}_{3}$ co-catalysts. Fast dehydrogenation-hydrogenation reactions at $\mathrm{Pt}$ sites equilibrate alkanes and all alkene isomers of a given backbone structure at these sites providing a low and constant concentration of alkenes that disfavor oligomerization reactions at acid sites that can lead to catalyst deactivation. Alkenes isomerize to one another through alkoxide backbone rearrangements at acid sites via similar elementary steps and with similar rate expressions. Alkene isomerization rate constants for each hexane isomer $\left(\mathrm{k}_{\mathrm{isom}, \mathrm{R}} \mathrm{K}_{\text {prot, } \mathrm{R}}\right)$ were measured on Keggin polyoxometalate (POM) clusters using mechanism-based interpretations of rate data and titrations that count the number of reactive $\mathrm{H}^{+}$. These rate constants reflect the stabilities of cycloalkyl carbenium ion transition states, which mediate kinetically-relevant alkoxide isomerization steps, relative to an equilibrated lump of gaseous reactant alkenes and unoccupied sites; rate constants decrease exponentially with increasing deprotonation energies (DPE) on Keggin POM for 
all reactants because ion-pair transition states contain less stable conjugate anions on weaker acids. Such transition states attenuate changes in DPE on activation barriers because interactions between the conjugate anion and cationic moieties at these transition states recover most of the additional energy needed to deprotonate weaker acids, resulting in large changes in DPE having relatively small impacts on activation energies $\left(\mathrm{d}\left(\mathrm{E}_{\mathrm{A}, \mathrm{R}}\right) / \mathrm{d}(\mathrm{DPE})=0.11\right)$.

Measured selectivities reflected, in part, transport restrictions of product alkenes within acid domains instead of the rate constants for the formation of individual products from each reactant. In such cases, selectivities to isomerization products formed from reactant-derived alkenes after only a single sojourn at an acid site cannot be estimated directly from measured selectivities, because secondary interconversions of alkene products are similar in rates to their hydrogenation, both locally within acid domains via hydrogen transfer from alkane reactants or via reactions with $\mathrm{H}_{2}$ after their diffusion through such acid domains to reach Pt sites. The rate constant for the formation of $3 \mathrm{MP}$ from $2 \mathrm{MP}$ reactants, and consequently the $2 \mathrm{MP}$ isomerization selectivity to $3 \mathrm{MP}$ and the ratio of this to that for isomerization products that vary backbone length $\left(\mathrm{s}_{\mathrm{MS}}\right)$, were determined explicitly, without the use of measured product selectivities, from mechanism-based interpretations of measured turnover rates for all hexane isomer reactants on each catalyst mixture. Determined $\mathrm{s}_{\mathrm{MS}}$ values and, consequently, the tendency for alkenes to methyl-shift, branch, or chain lengthen were unaffected by the DPE, and thus the acid strength, of POM clusters because of the similar amount and localization of cationic charge at all isomerization transition states. 
These findings show unequivocally that the demanding or facile nature of a given reaction, which is a property of the stability of the organic cations at ion pair transition states, is not necessarily relevant to how these catalytic reactions "sense" acid strength changes; this depends on the amount and localization of cationic charge at such transition states. These concepts suggest changing acid strength will lead to more selective conversions of reactant mixtures only when competing pathways are mediated by transition states with different amount or localization of cationic charge, thus showing that isomerization selectivities, often used to assess acid strength, are inappropriate probes of acid strength in the context proposed by, and used in, the previous literature. Although shown here for isomerization reactions, these concepts apply in general to reactions mediated by ion-pairs at transition states. 


\section{Acknowledgements}

The support by the Chemical Sciences, Geosciences, Biosciences Division, Office of Basic Energy Sciences, Office of Science US Department of Energy under grant number DE-FG02-03ER15479 is gratefully acknowledged. We thank Dr. Cindy Yin (UCBerkeley) and Dr. Stuart Soled (Exxon Mobile) for their assistance with the synthesis of unsupported $\mathrm{H}_{5} \mathrm{AlW}_{12} \mathrm{O}_{40}$ and Dr. George Meitzner for his technical review of this manuscript. 
[1] A. Corma, Chem. Rev. 95 (1995) 559.

[2] M.J. Janik, J. Macht, E. Iglesia, M. Neurock, J. Phys. Chem. C. 113 (2009) 1872.

[3] J. Macht, M.J. Janik, M. Neurock, E. Iglesia, J. Am. Chem. Soc. 130 (2008) 10369.

[4] M. Brändle, J. Sauer, J. Am. Chem. Soc. 120 (1998) 1556.

[5] A.J. Jones, R.T. Carr, S.I. Zones, E. Iglesia, J.Catal. 312 (2014) 58.

[6] J. Macht, M.J. Janik, M. Neurock, E. Iglesia, Angew. Chem., Int. Ed. 46 (2007) 7864.

[7] R. Carr, M. Neurock, E. Iglesia, J. Catal. 278 (2011) 78.

[8] J. Macht, R.T. Carr, E. Iglesia, J. Am. Chem. Soc. 131 (2009) 6554.

[9] P. Deshlahra, R.T. Carr, E. Iglesia, Ionic and Covalent Stabilization of Intermediates and Transition

States in Catalysis by Solid Acids, In preparation.

[10] P.B. Weisz, E.W. Swegler, Science 126 (1957) 31.

[11] M. Guisnet, F. Alvarez, G. Giannetto, G. Perot, Catal. Today 1 (1987) 415.

[12] G.D. Pirngruber, K. Seshan, J. Lercher, J. Catal. 186 (1999) 188.

[13] J.J. Cowan, C.L. Hill, R.S. Reiner, I.A.Weinstock, Inorg. Synth. 33 (2002) 18.

[14] L.C. Baker, T.P. McCutcheon, J. Am. Chem. Soc. 78 (1956) 4503.

[15] L.C. Baker, T.P. McCutcheon, J. Am. Chem. Soc. 72 (1950) 2374.

[16] D.W. Scott, Chemical thermodynamic properties of hydrocarbons and related substances: properties of the alkane hydrocarbons, $\mathrm{C} 1$ through $\mathrm{C} 10$, in the ideal gas state from 0 to $1500 \mathrm{~K}$, U.S. Bureau of Mines, Washington, 1974.

[17] C.D. Baertsch, K.T. Komala, Y.-H. Chua, E. Iglesia, J. Catal. 205 (2002) 44.

[18] N. Mizuno and M. Misono, Chem. Rev. 98 (1998) 199.

[19] B.B. Bardin, R.J. Davis, Appl. Cat. A. 200 (2000) 219.

[20] M. Janik, B. Bardin, R. Davis, M. Neurock, J. Phys. Chem. B. 110 (2006) 4170.

[21] X. Rozanska, P. Sautet, F. Delbecq, F. Lefebvre, S. Borshch, H. Chermette, J.-M. Basset, E.

Grinenval, Phys. Chem. Chem. Phys. 13 (2011) 15955.

[22] T. Okuhara, N. Mizuno, M. Misono, Adv. Catal. 41 (1996) 113.

[23] G. Djéga-Mariadassou, M. Boudart, J. Catal. 216 (2003) 89.

[24] R. Madon, M. Boudart, Ind. Eng. Chem. Fundam. 21 (1982) 438.

[25] J. Macht, R.T. Carr, E. Iglesia, J. Catal. 264 (2009) 54.

[26] V.B. Kazansky, Acc. Chem. Res. 24 (1991) 379.

[27] M.A. Natal-Santiago, R. Alcalá, J. A. Dumesic, J. Catal. 181 (1999) 124.

[28] M. Boronat, P. Viruela, A. Corma, J. Phys. Chem. 100 (1996) 16514.

[29] T. Demuth, X. Rozanska, L. Benco, J. Hafner, R.A. van Santen, H. Toulhoat, J. Catal. 214 (2003) 68.

[30] A L.L East, T. Bucko, J. Hafner, J. Phys. Chem. A 111 (2007) 5945.

[31] R.A. Alberty, C.A. Gehrig, J. Phys. Chem. Ref. Data. 14 (1985) 803. 
Table 1. Number of accessible $\mathrm{H}^{+}$per POM cluster measured by chemical titration with 2,6-di-tertbutylpyridine $^{\mathrm{a}}$ during 2-methylpentane isomerization ${ }^{b}$ on $\mathrm{HXW}_{12} \mathrm{O}_{40} / \mathrm{SiO}_{2}-\mathrm{Pt}_{/} \mathrm{Al}_{2} \mathrm{O}_{3}(\mathrm{X}=\mathrm{P}, \mathrm{Si}, \mathrm{Al}, \mathrm{Co}$ ) mixtures.

\begin{tabular}{|c|c|c|c|}
\hline Catalyst & $\begin{array}{l}\text { POM Content } \\
(\% \text { wt. })\end{array}$ & 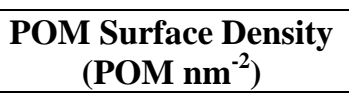 & $\begin{array}{c}\text { Accessible } \mathbf{H}^{+} \\
\text {(per POM) }\end{array}$ \\
\hline $\mathrm{H}_{3} \mathrm{PW}_{12} \mathrm{O}_{40}$ & 5 & 0.04 & $0.72^{\mathrm{c}}, 0.73^{\mathrm{d}}, 1.1^{\mathrm{e}}$ \\
\hline $\mathrm{H}_{3} \mathrm{PW}_{12} \mathrm{O}_{40}$ & 25 & 0.20 & 1.6 \\
\hline $\mathrm{H}_{4} \mathrm{SiW}_{12} \mathrm{O}_{40}$ & 5 & 0.04 & 1.6 \\
\hline $\mathrm{H}_{5} \mathrm{AlW}_{12} \mathrm{O}_{40}$ & 5 & 0.04 & 1.45 \\
\hline $\mathrm{H}_{6} \mathrm{CoW}_{12} \mathrm{O}_{40}$ & 5 & 0.04 & 0.25 \\
\hline
\end{tabular}

${ }^{a}$ Assuming a 1:1 DTBP: $\mathrm{H}^{+}$adsorption stoichiometry

${ }^{\mathrm{b}} 1.9 \mathrm{kPa}$ 2-methylpentane, $75 \mathrm{kPa} \mathrm{H}, 473 \mathrm{~K}$

${ }^{\mathrm{c}} \mathrm{Pt}_{\mathrm{S}} / \mathrm{H}^{+}=11.7$

${ }^{\mathrm{d}} \mathrm{Pt}_{\mathrm{S}} / \mathrm{H}^{+}=6.2$

${ }^{\mathrm{e}} \mathrm{Pt}_{\mathrm{S}} / \mathrm{H}^{+}=22.9$

Table 2. 2-Methylpentane isomerization rate constants $\left(\mathrm{k}_{\mathrm{isom}, 2} \mathrm{~K}_{\mathrm{prot}, 2}\right.$ and $\left.\mathrm{k}_{\mathrm{isom}, 2}\right)$ and protonation equilibrium constants $\left(\mathrm{K}_{\text {prot,2}}\right)$ measured on $\mathrm{HXW}_{12} \mathrm{O}_{40} / \mathrm{SiO}_{2}-\mathrm{Pt}_{2} \mathrm{Al}_{2} \mathrm{O}_{3}(\mathrm{X}=\mathrm{P}, \mathrm{Si}, \mathrm{Al}, \mathrm{Co})$ mixtures (473 K)

\begin{tabular}{|l|c|c|c|}
\hline Catalyst & $\mathbf{k}_{\text {isom, } \mathbf{2}} \mathbf{K}_{\text {prot } \mathbf{2}}^{\mathbf{a , d}}$ & $\mathbf{k}_{\text {isom, } \mathbf{2}}^{\mathbf{b , d}}$ & $\mathbf{K}_{\text {prot }, \mathbf{2}}^{\mathbf{c , d}}$ \\
\hline $\mathrm{H}_{3} \mathrm{PW}_{12} \mathrm{O}_{40}$ & $1759 \pm 5$ & $1200 \pm 170$ & $1.5 \pm 0.2$ \\
\hline $\mathrm{H}_{4} \mathrm{SiW}_{12} \mathrm{O}_{40}$ & $1159 \pm 9$ & $1100 \pm 1300$ & $1.0 \pm 1.2$ \\
\hline $\mathrm{H}_{5} \mathrm{AlW}_{12} \mathrm{O}_{40}$ & $771 \pm 4$ & $187 \pm 11$ & $4.1 \pm 0.2$ \\
\hline $\mathrm{H}_{6} \mathrm{CoW}_{12} \mathrm{O}_{40}$ & $393 \pm 3$ & $108 \pm 14$ & $3.6 \pm 0.5$ \\
\hline
\end{tabular}

${ }^{\mathrm{a}} 10^{-3}$ molecules $\left(\mathrm{Pa} \mathrm{H}^{+} \mathrm{s}\right)^{-1}$

${ }^{\mathrm{b}} 10^{-3}$ molecules $\left(\mathrm{H}^{+} \mathrm{s}\right)^{-1}$

${ }^{\mathrm{c}} \mathrm{Pa}^{-1}$

${ }^{\mathrm{d}}$ Errors represent the $95 \%$ confidence intervals of parameter in Eq. 4 obtained from the method of least-squares.

Table 3. 3MP, 23DMB, and $\mathrm{nH}$ isomerization rates measured on $\mathrm{H}_{3} \mathrm{PW} / \mathrm{SiO}_{2}-\mathrm{Pt} / \mathrm{Al}_{2} \mathrm{O}_{3}$ mixtures

\begin{tabular}{|c|c|c|c|c|}
\hline 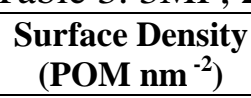 & $\begin{array}{l}\mathbf{P t}_{\mathrm{s}} / \mathbf{H}^{+} \\
\text {Ratio }\end{array}$ & $\begin{array}{c}\text { 3MP Turnover } \\
\text { Rate }^{\text {a,b }}\end{array}$ & $\begin{array}{c}\text { 23DMB Turnover } \\
\text { Rate }^{\mathbf{a}, \mathbf{b}}\end{array}$ & $\begin{array}{c}\text { nH Turnover } \\
\text { Rate }^{\mathrm{a}, \mathrm{b}}\end{array}$ \\
\hline 0.04 & 11.7 & 75 & 32 & 7.5 \\
\hline 0.04 & 22.9 & 80 & 30 & 9.4 \\
\hline 0.25 & 10.5 & 73 & 32 & 7.2 \\
\hline
\end{tabular}

${ }^{\mathrm{a}} 10^{-3}$ molecules $\left(\mathrm{H}^{+} \mathrm{s}\right)^{-1}$

b $1.9 \mathrm{kPa}$ alkane, $75 \mathrm{kPa} \mathrm{H}_{2}, 473 \mathrm{~K}$ 


\section{Figure and Scheme Captions}

Figure 1. 2-Methylpentane isomerization rates (per POM) on $(O) \mathrm{H}_{3} \mathrm{PW} / \mathrm{SiO}_{2}-\mathrm{Pt} / \mathrm{Al}_{2} \mathrm{O}_{3}\left(\mathrm{Pt}_{\mathrm{S}} / \mathrm{H}^{+}=\right.$ 11.7) and $(\diamond) \mathrm{H}_{4} \mathrm{SiW} / \mathrm{SiO}_{2}-\mathrm{Pt} / \mathrm{Al}_{2} \mathrm{O}_{3}\left(\mathrm{Pt}_{\mathrm{S}} / \mathrm{H}^{+}=4.8\right)$ mixtures as a function of time before 2,6-ditert-butylpyridine introduction $\left(473 \mathrm{~K}, 1.9 \mathrm{kPa} 2 \mathrm{MP}, 75 \mathrm{kPa} \mathrm{H}_{2}\right)$ and as a function of cumulative titrant uptake (473 K, $1.9 \mathrm{kPa} 2 \mathrm{MP}, 75 \mathrm{kPa} \mathrm{H}_{2}, 0.45 \mathrm{~Pa}$ DTBP).

Figure 2. 2-Methylpentane isomerization turnover rates as a function of $\left(2 \mathrm{MP} / \mathrm{H}_{2}\right)$ ratios on $\mathrm{H}_{3} \mathrm{PW} / \mathrm{SiO}_{2}-\mathrm{Pt} / \mathrm{Al}_{2} \mathrm{O}_{3}$ mixtures with $(\diamond) 0.03 \mathrm{H}^{+}\left[\mathrm{nm}-\mathrm{SiO}_{2}\right]^{-2}$ and $\mathrm{Pt}_{\mathrm{S}} / \mathrm{H}^{+}=6.2$, ( $) 0.03 \mathrm{H}^{+}[\mathrm{nm}-$ $\left.\mathrm{SiO}_{2}\right]^{-2}$ and $\mathrm{Pt}_{\mathrm{S}} / \mathrm{H}^{+}=11.7,(\triangle) 0.04 \mathrm{H}^{+}\left[\mathrm{nm}-\mathrm{SiO}_{2}\right]^{-2}$ and $\mathrm{Pt}_{\mathrm{S}} / \mathrm{H}^{+}=22.9$, and (口) $0.34 \mathrm{H}^{+}[\mathrm{nm}-$ $\left.\mathrm{SiO}_{2}\right]^{-2}$ and $\mathrm{Pt}_{\mathrm{S}} / \mathrm{H}^{+}=10.5$ (reaction conditions: $473 \mathrm{~K}, 0.5-25 \mathrm{kPa} 2 \mathrm{MP}, 75 \mathrm{kPa} \mathrm{H}_{2}$ ). Dashed lines represent the regression of the data to the functional form of Eq. 4.

Figure 3. Isomerization selectivities to 23DMB $(\mathbf{O})$ and $\mathrm{nH}(\boldsymbol{\square})$ products for $2 \mathrm{MP}$ reactants on $\mathrm{H}_{3} \mathrm{PW} / \mathrm{SiO}_{2}-\mathrm{Pt} / \mathrm{Al}_{2} \mathrm{O}_{3}\left(\mathrm{Pt}_{\mathrm{S}} / \mathrm{H}^{+}=10.5-11.7 ; \mathrm{H}^{+}\left[\mathrm{nm}-\mathrm{SiO}_{2}\right]^{-2}=0.03-0.34\right)$ as a function of $2 \mathrm{MP}$ pressure (473 K, 0.7 - $25 \mathrm{kPa} 2 \mathrm{MP}, 75 \mathrm{kPa} \mathrm{H}_{2}$ ).

Figure 4. (a) 2-Methylpentane isomerization turnover rates as functions of the $\left(2 \mathrm{MP} / \mathrm{H}_{2}\right)$ ratio and (b) inverse 2-methylpentane isomerization turnover rates as a function of the $\left(\mathrm{H}_{2} / 2 \mathrm{MP}\right)$ ratio on mixtures of $\mathrm{Pt} / \mathrm{Al}_{2} \mathrm{O}_{3}$ with $(\bigcirc) \mathrm{H}_{3} \mathrm{PW} / \mathrm{SiO}_{2}\left(\mathrm{Pt}_{\mathrm{S}} / \mathrm{H}^{+}=11.7\right),(\diamond) \mathrm{H}_{4} \mathrm{SiW} / \mathrm{SiO}_{2}\left(\mathrm{Pt}_{\mathrm{S}} / \mathrm{H}^{+}=4.8\right)$, ( $\Delta$ ) $\mathrm{H}_{5} \mathrm{AlW} / \mathrm{SiO}_{2}\left(\mathrm{Pt}_{\mathrm{S}} / \mathrm{H}^{+}=5.0\right)$, and $(\boldsymbol{\square}) \mathrm{H}_{6} \mathrm{CoW} / \mathrm{SiO}_{2}\left(\mathrm{Pt}_{\mathrm{S}} / \mathrm{H}^{+}=5.9\right)$ (reaction conditions: 473 $\mathrm{K}, 0.5-25 \mathrm{kPa} 2 \mathrm{MP}, 60-90 \mathrm{kPa} \mathrm{H}_{2}$ ). Dashed lines represent the regression of the data to the functional form of Eq. 4.

Figure 5. (a) Isomerization turnover rates as functions of the $\left([\mathrm{R}] / \mathrm{H}_{2}\right)$ ratio and (b) inverse isomerization turnover rates as functions of the $\left(\mathrm{H}_{2} /[\mathrm{R}]\right)$ ratio for $(\diamond) 3$-methylpentane, $(\square)$ 2,3dimethylbutane, and $(\boldsymbol{\Delta})$ n-hexane reactants on $\mathrm{H}_{3} \mathrm{PW} / \mathrm{SiO}_{2}-\mathrm{Pt} / \mathrm{Al}_{2} \mathrm{O}_{3}\left(\mathrm{Pt}_{\mathrm{S}} / \mathrm{H}^{+}=11.7\right.$ ) (reaction conditions: $473 \mathrm{~K}, 0.5-25 \mathrm{kPa}$ alkane, $60-90 \mathrm{kPa} \mathrm{H}_{2}$ ). Dashed lines represent the regression of the data to the functional form of Eq. 5.

Figure 6. (a) Alkene isomerization rate constants $\left(\mathrm{k}_{\mathrm{isom}, \mathrm{R}} \mathrm{K}_{\text {prot,R}}\right)$ for $(\mathbf{O})$ 2-methylpentane, ( $\left.\mathbf{\Delta}\right) 3$ methylpentane, (ם) 2,3-dimethylbutane, and ( $)$ n-hexane reactants and (b)

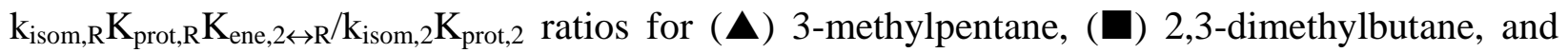
$(\checkmark)$ n-hexane reactants as functions of deprotonation energy for $\mathrm{H}_{8-\mathrm{n}} \mathrm{X}^{\mathrm{n}+} \mathrm{W}_{12} \mathrm{O}_{40}(\mathrm{X}=\mathrm{P}, \mathrm{Si}, \mathrm{Al}$, Co) $(473 \mathrm{~K})$. The dashed lines in (a) are exponential fits of the data to deprotonation energies for Keggin clusters and in (b) are the averages of the data for each ratio.

Figure 7. Rate constants for 2-methylpentene isomerization to 3 -methylpentene $\left(\mathrm{k}_{\mathrm{isom}, 2 \rightarrow 3} \mathrm{~K}_{\text {prot }, 2}\right.$, O) and selectivities for methyl shift isomerization events relative to isomerization events that vary backbone length ( $\left.\mathrm{s}_{\mathrm{MS}}, \mathbf{0}\right)$ at $473 \mathrm{~K}$ as a function of deprotonation energy for $\mathrm{H}_{8-\mathrm{n}} \mathrm{X}^{\mathrm{n}+} \mathrm{W}_{12} \mathrm{O}_{40}$ $\left(\mathrm{X}=\mathrm{P}, \mathrm{Si}, \mathrm{Al}, \mathrm{Co}\right.$ ). The dashed lines are an exponential fit of $\mathrm{k}_{2 \rightarrow 3}$ values to deprotonation energies and the average of $\mathrm{s}_{\mathrm{MS}}$ values for Keggin clusters. 
Scheme 1. Isomerization reaction network for gaseous hexane/hexene isomers on $\mathrm{POM} / \mathrm{SiO}_{2}$ mixtures with $\mathrm{Pt} / \mathrm{Al}_{2} \mathrm{O}_{3}$

Scheme 2. Elementary steps and chemical reactions involved in 2-methylpentane isomerization on metal-acid mixtures that establish 2-methylpentane/2-methylpentene equilibrium. Chemical reactions are shown for the (de)hydrogenation on metal sites $\left(\mathrm{Pt}^{2} / \mathrm{Al}_{2} \mathrm{O}_{3}\right)$ and elementary steps for acid-catalyzed routes on $\mathrm{H}_{8-\mathrm{n}} \mathrm{X}^{\mathrm{n+}} \mathrm{W}_{12} \mathrm{O}_{40} / \mathrm{SiO}_{2}\left(\mathrm{X}=\mathrm{P}^{5+}, \mathrm{Si}^{4+}, \mathrm{Al}^{3+}, \mathrm{Co}^{2+}\right)$. Steps $3-6$ are illustrated using 3-methylpentane as the product, but analogous steps are involved in 2,3dimethylbutane and n-hexane formation. Bonds to the Brønsted active site are denoted as "*" in molecular structures.

Scheme 3. Reaction coordinate diagram depicting the free energies of $2 \mathrm{MP}=\left(\mathrm{G}_{\mathrm{ene}, 2}\right), 3 \mathrm{MP}=$ $\left(\mathrm{G}_{\mathrm{ene}, 3}\right)$, and $23 \mathrm{DMB}=\left(\mathrm{G}_{\mathrm{ene}, 23}\right)$ regioisomer isomer groups and the free energies of the isomerization transition states accessible to each of these groups $\left(2 \mathrm{MP}^{=}: \mathrm{G}_{2 \leftrightarrow 3}^{\ddagger}, \mathrm{G}^{\ddagger}{ }^{\ddagger} 23\right.$, and $\mathrm{G}^{\ddagger}{ }_{2 \leftrightarrow \mathrm{nH}} ; 3 \mathrm{MP}^{=}: \mathrm{G}_{2 \leftrightarrow 3}^{\ddagger}, \mathrm{G}^{\ddagger}{ }_{3 \leftrightarrow 23}$ and $\mathrm{G}_{3 \leftrightarrow \mathrm{nH}}^{\ddagger} ; 23 \mathrm{DMB}^{=}: \mathrm{G}_{2 \leftrightarrow 23}^{\ddagger}$ and $\mathrm{G}_{3 \leftrightarrow 23}^{\ddagger}$ ). Free energy barriers

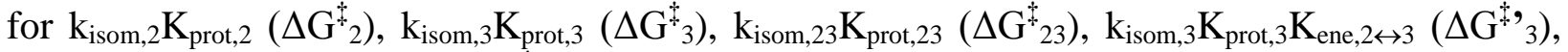

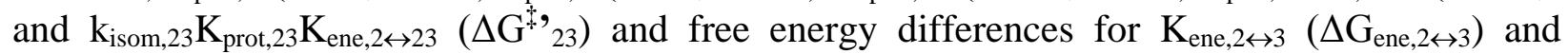
$\mathrm{K}_{\text {ene, } 2 \leftrightarrow 23}\left(\Delta \mathrm{G}_{\mathrm{ene}, 2 \leftrightarrow 23}\right)$ are also shown.

Scheme 4. Thermochemical cycle accounting for activation energies of Brønsted acid-catalyzed isomerization reactions (shown for $3 \mathrm{MP}$ products). Activation energies of $\mathrm{k}_{\mathrm{isom}, 2 \rightarrow 3} \mathrm{~K}_{\text {prot,2 }}\left(\mathrm{E}_{\mathrm{A}, 2 \rightarrow 3}\right)$ are the sum of the intrinsic isomerization activation energies $\left(\mathrm{E}_{\mathrm{isom}, 3 \mathrm{MP}}\right)$ and 2-methylpentene protonation energies at the acid site $\left(\mathrm{E}_{\mathrm{prot}}\right) . \mathrm{E}_{\mathrm{A}, 2 \rightarrow 3}$ values depend on catalyst deprotonation energies (DPE), gas-phase protonation of the alkene to form the gaseous analog of the transition state $\left(E_{\text {gas }, 2 \rightarrow 3}\right)$, and transition state interaction energies $\left(E_{\mathrm{int}, 2 \rightarrow 3}\right)$.

Scheme 5. Proposed cyclopropyl carbenium ions at isomerization transition states forming (A) 3methylpentane, (B) 2,3-dimethylbutane, and (C) n-hexane [27]. 3-Methylpentane transition states involve cleavage and formation of $\mathrm{C}$ - $\mathrm{C}$ bonds to shift the methyl group along the hydrocarbon backbone. 2,3-Dimethylbutane and n-hexane transition states involve concerted cleavage and formation of $\mathrm{C}-\mathrm{C}$ and $\mathrm{C}-\mathrm{H}$ bonds to rearrange the hydrocarbon backbone. 